\title{
Review
}

\section{Algae and Their Metabolites as Potential Bio-Pesticides}

\author{
Elias Asimakis ${ }^{1}$, Awad A. Shehata ${ }^{2}$, Wolfgang Eisenreich ${ }^{3}{ }^{\circledR}$, Fatma Acheuk ${ }^{4}$, Salma Lasram ${ }^{5}$, \\ Shereen Basiouni ${ }^{6}$, Mevlüt Emekci ${ }^{7}$, Spyridon Ntougias ${ }^{8}\left(\mathbb{D}\right.$, Gökçe Taner ${ }^{9}{ }^{(D}$, Helen May-Simera ${ }^{6}(\mathbb{D}$, \\ Mete Yilmaz ${ }^{9, *}$ and George Tsiamis ${ }^{1, *(\mathbb{D})}$
}

check for updates

Citation: Asimakis, E.; Shehata, A.A.; Eisenreich, W.; Acheuk, F.; Lasram, S.; Basiouni, S.; Emekci, M.; Ntougias, S. Taner, G.; May-Simera, H.; et al. Algae and Their Metabolites as Potential Bio-Pesticides. Microorganisms 2022, 10, 307. https://doi.org/10.3390/ microorganisms10020307

Academic Editors: Marcin Ożarowski and Tomasz M. Karpiński

Received: 10 December 2021

Accepted: 25 January 2022

Published: 27 January 2022

Publisher's Note: MDPI stays neutral with regard to jurisdictional claims in published maps and institutional affiliations.

Copyright: (C) 2022 by the authors. Licensee MDPI, Basel, Switzerland. This article is an open access article distributed under the terms and conditions of the Creative Commons Attribution (CC BY) license (https:// creativecommons.org/licenses/by/ $4.0 /)$.
1 Laboratory of Systems Microbiology and Applied Genomics, Department of Environmental Engineering, University of Patras, 2 Seferi St., 30131 Agrinio, Greece; eliasasim@gmail.com

2 Research and Development Section, PerNaturam GmbH, 56290 Gödenroth, Germany; awad.shehata@pernaturam.de

3 Bavarian NMR Center-Structural Membrane Biochemistry, Department of Chemistry, Technische Universität München, 85748 Garching, Germany; wolfgang.eisenreich@mytum.de

4 Laboratory for Valorization and Conservation of Biological Resources, Faculty of Sciences, University M'Hamed Bougara of Boumerdes, Boumerdes 35000, Algeria; fatma.acheuk@yahoo.fr

5 Laboratory of Molecular Physiology of Plants, Borj-Cedria Biotechnology Center. BP. 901, Hammam-Lif 2050, Tunisia; Salma.lasram.cbbc@gmail.com

6 Institute of Molecular Physiology, Johannes Gutenberg-University of Mainz, 55128 Mainz, Germany; shereen.basiouni@klinik.uni-regensburg.de (S.B.); hmaysime@uni-mainz.de (H.M.-S.)

7 Department of Plant Protection, Faculty of Agriculture, Ankara University, Keçiören, Ankara 06135, Turkey; Mevlut.Emekci@agri.ankara.edu.tr

8 Department of Environmental Engineering, Democritus University of Thrace, Vas. Sofias 12, 67132 Xanthi, Greece; sntougia@env.duth.gr

9 Department of Bioengineering, Bursa Technical University, Bursa 16310, Turkey; gokce.taner@btu.edu.tr

* Correspondence: mete.yilmaz@btu.edu.tr (M.Y.); gtsiamis@upatras.gr (G.T.)

Abstract: An increasing human population necessitates more food production, yet current techniques in agriculture, such as chemical pesticide use, have negative impacts on the ecosystems and strong public opposition. Alternatives to synthetic pesticides should be safe for humans, the environment, and be sustainable. Extremely diverse ecological niches and millions of years of competition have shaped the genomes of algae to produce a myriad of substances that may serve humans in various biotechnological areas. Among the thousands of described algal species, only a small number have been investigated for valuable metabolites, yet these revealed the potential of algal metabolites as bio-pesticides. This review focuses on macroalgae and microalgae (including cyanobacteria) and their extracts or purified compounds, that have proven to be effective antibacterial, antiviral, antifungal, nematocides, insecticides, herbicides, and plant growth stimulants. Moreover, the mechanisms of action of the majority of these metabolites against plant pests are thoroughly discussed. The available information demonstrated herbicidal activities via inhibition of photosynthesis, antimicrobial activities via induction of plant defense responses, inhibition of quorum sensing and blocking virus entry, and insecticidal activities via neurotoxicity. The discovery of antimetabolites also seems to hold great potential as one recent example showed antimicrobial and herbicidal properties. Algae, especially microalgae, represent a vast untapped resource for discovering novel and safe biopesticide compounds.

Keywords: cyanobacteria; algal extracts; antimicrobial; plant defense; photosynthesis

\section{Introduction}

The term algae encompasses a wide range of photosynthetic organisms that are found primarily in freshwater and marine environments, although certain representatives can thrive in terrestrial niches, either on their own or by developing symbiotic relationships with other organisms [1,2]. Larger eukaryotic algae, such as seaweeds, are called macroalgae, while smaller unicellular eukaryotes are collectively referred to as microalgae. On the other hand, cyanobacteria (blue-green algae) represent the prokaryotic clade of this highly 
diverse group [2]. Moreover, some genera exhibit extraordinary growth potential in terms of produced biomass within a short period of time [3,4].

Due to the high biomass production potential and their ability to grow relatively quickly, recent research on algae has been primarily focused on biofuel production. They are more promising alternatives than plant-based biofuel production, because, unlike plants, they do not require fertile land for growth; thus, they do not interfere with food production $[2,5,6]$. However, significant research effort has been made in recent years in identifying and isolating bioactive compounds from algae. These compounds may possess pharmaceutical or biomedical value and can be used in anticoagulant, antioxidant, antitumor, antimicrobial, immunomodulatory, antilipidemic, hypoglycemic, and anti-inflammatory products [7-10]. Algae and their metabolites can also be used in cosmetics due to their antioxidant or tissue regenerative action and in the food industry, due to their high content of fibers, minerals, vitamins, pigments, and antioxidants [8]. In terms of biochemical properties, these metabolites can be lipids, proteins, peptides, polysaccharides, carotenoids, phenolics, and alkaloids $[5,11]$. Such bioactive compounds can be produced on an industrial and agricultural scale, providing substantial economic benefits [8]. Furthermore, recent advancements in microalgae biotechnology have made it possible to use microalgae as bioreactors for recovering recombinant proteins and medicinal products such as vaccines, antibodies, immunotoxins, and antimicrobial agents $[3,12]$.

Algae and their extracts also display antimicrobial, nematocidal, herbicidal, and insecticidal/acaricidal properties against crop pathogens and can be used as biopesticides [13-15]. The term biopesticide may encompass naturally occurring compounds (e.g., sodium bicarbonate, sodium acetate), biochemical substances that are produced naturally by various organisms or by genetically-modified plants, as well as microorganisms (bacteria, viruses, fungi, algae etc.) that are used to control pests in agricultural practices. In this regard, algal components have been shown to efficiently suppress plant pathogenic bacteria, including the genera Agrobacterium, Pseudomonas, Xanthomonas, and Erwinia, which are associated with serious diseases of important crops that form the nutritional basis of most human societies, such as rice and potato plants [16-18]. Similar effects have been identified against the most common plant pathogens, fungi. Algal extracts can inhibit mycelial growth and induce resistance in plants against widespread fungal genera such as Fusarium, Verticillium, Rhizoctonia, Phytophthora, and Phoma [18-20]. Their antimicrobial activity also expands to viral pathogens, such as tobacco mosaic virus (TMV) and potato virus X (PVX), which are inhibited either directly or by inducing plant defense mechanisms [21-23]. As well as effectively controlling pathogenic microorganisms, algal extracts have been tested with success against animal targets. These targets include soil-borne nematodes, plant or fruit feeding insects (e.g., fruit fly larvae) and mites, as well as insects that mediate transmission of diseases [24-27]. Herbaceous weeds that hinder crop development, as well as algal species that grow uncontrollably resulting in harmful algal blooms, can also be treated with algal products. The effect in these cases, are either based on cytotoxicity or the inhibition of photosynthesis [28,29].

The use of natural products against pests in agricultural practices instead of synthetic chemicals shows significant advantages. These compounds are environmentally safe due to their high biodegradability and low residuality, are safer to non-target organisms due to better specificity, and are less likely to produce resistance due to diverse mechanisms of action [30]. Besides, there is an increasing interest to identify and recover such bioactive compounds from various kinds of algae that can be used for plant protection purposes in the context of sustainable agricultural practices. This review focuses on the current knowledge of algal bioactive substances with known pesticidal action.

\section{Biological Roles of Algal Compounds or Extracts}

\subsection{Antibacterial Action}

An array of diverse chemical compounds from algae, including alkaloids, polyketides, peptides, polysaccharides, phlorotannins, diterpenes, sterols, quinones, lipids, and glyc- 
erols, have been found to exhibit antibacterial action [14,31]. However, in some instances, the specific compounds with antibacterial properties are not fully elucidated, and the activity is collectively attributed to algal extracts. Also, as most studies focus on the antibacterial properties of algal extracts on human pathogens, information on plant pathogens is scarce but is constantly being enriched. An excellent example of algal extracts with antibacterial action comes from the brown marine alga Sargassum wightii (Table 1).

The methanolic extracts of this species showed maximum antibacterial activity against the plant pathogen Pseudomonas syringae, to prevent leaf spot disease of the medicinal herb Gymnema sylvestre [32]. Similar in vitro activity against the phytopathogenic bacterium Xanthomonas oryzae was observed by the macroalgae Gracilaria edulis, Sargassum wightii, and Enteromorpha flexuosa [16]. The compound that was responsible for this action in the brown alga Sargassum wightii was the sulphoglycerolipid 1-O-palmitoyl-3$\mathrm{O}\left(6^{\prime}\right.$-sulpho-a-quinovopyranosyl)-glycerol (Figure 1) from the methanolic extract [33]. The plant pathogens Xanthomonas campestris and Erwinia carotovora were also inhibited in vitro by the methanol-soluble and insoluble extracts of Ulva fasciata [34]. The spray application of aqueous extracts from the brown algae Cystoseira myriophylloides and Fucus spiralis significantly reduced Crown gall disease incidence that was caused by the bacterial pathogen Agrobacterium tumefaciens in greenhouse tomato plants (Solanum lycopersicum) [18]. The response was related to oxidative burst mechanisms since the treated plants exhibited significantly greater activity levels of the plant defense enzymes polyphenol oxidase and peroxidase. The methanolic extract of the marine brown algae Sargassum latifolium, Hydroclathrus clathratus, and Padina gymnospora showed antibacterial activity against the soil-borne phytopathogenic bacteria Ralstonia solanacearum and Pectobacterium carotovorum. The extract of Padina gymnospora, which showed the most potent effect, was dominated by palmitic and oleic acids (Figure 1) [35].

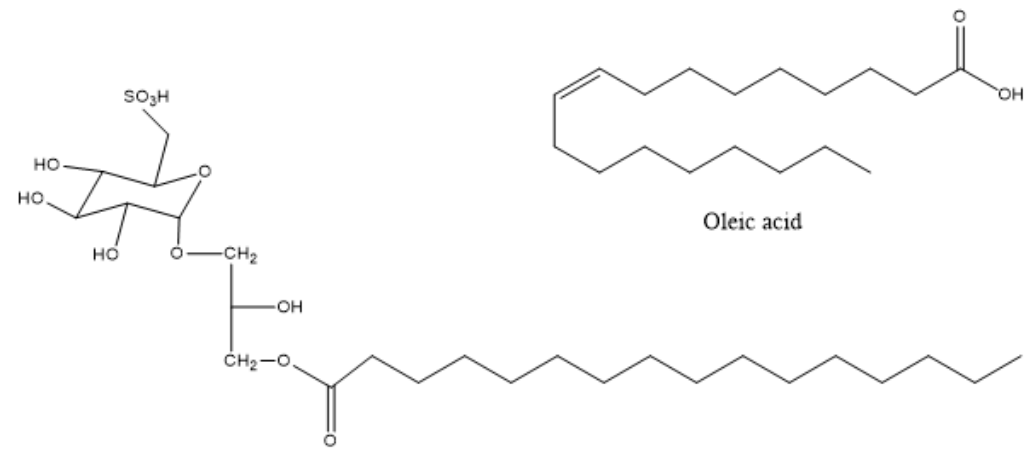

1-O-Palmitoyl-3-O(6'-sulpho- $\alpha$-quinovopyranosyl)-glycerol

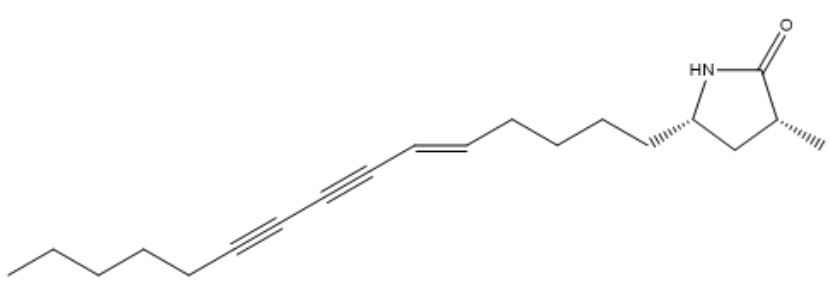

Fischerellin A

Figure 1. The chemical structure of active compounds that were isolated from Sargassum wightii, Padina gymnospora, and Fischerella muscicola.

In most documented cases, the antibacterial activity is against human or animal pathogens. In terms of agricultural practices, this is important for pathogenic bacteria that are associated with livestock. However, such agents could be further tested as potential candidates for plant protection applications, leaving ample room for future research $[19,36-47]$; such are the cases of the tetrabrominated diphenyl ether-like $2-\left(2^{\prime}, 4^{\prime}-\right.$ 
dibromophenoxy)-4,6-dibromoanisole (Figure 2) that was isolated from the green alga Cladaphora fascicularis that showed bactericidal action against Escherichia coli, Bacillus subtilis, and Staphylococcus aureus [38], and tetracyclic brominated diterpenes such as 3-hydroxy1-deoxy-bromotetraspaerol (Figure 3) from the red alga Sphaerococcus coronopifolius that exhibited antibacterial activity against a panel of $S$. aureus strains [36]. Interestingly, ethyl acetate extracts from two cyanobacterial species, Anabaena variabilis and A. circinalis, were effective against bacterial fish pathogens belonging to the genus Aeromonas, proving to be useful in aquaculture applications [48]. Moreover, as most of the published studies focus on macroalgae or cyanobacteria's antimicrobial activity, microalgae could constitute another exciting prospect for future research.

Table 1. Summary of algal compounds and their antibacterial activities.

\begin{tabular}{|c|c|c|c|c|c|c|}
\hline Algal Species & $\begin{array}{c}\text { Compound/Type } \\
\text { of Extract }\end{array}$ & Target Organism & $\begin{array}{c}\text { Disease/Pathogenic } \\
\text { Phenotype/Significance }\end{array}$ & $\begin{array}{c}\text { Protected } \\
\text { Plant/Organism }\end{array}$ & Mode of Action & Reference \\
\hline Sargassum wightii & $\begin{array}{l}\text { Methanolic } \\
\text { extracts }\end{array}$ & $\begin{array}{l}\text { Pseudomonas } \\
\text { syringae }\end{array}$ & Leaf spot disease & Gymnema sylvestre & NK & {$[32]$} \\
\hline $\begin{array}{l}\text { Gracilaria edulis, } \\
\text { Sargassum wightii, } \\
\text { Enteromorpha } \\
\text { flexuosa }\end{array}$ & $\begin{array}{c}\text { Petroleum ether } \\
\text { extracts, } \\
\text { methanolic } \\
\text { extracts, } \\
\text { unsaponified and } \\
\text { lipophilic } \\
\text { fractions }\end{array}$ & $\begin{array}{l}\text { Xanthomonas } \\
\text { oryzae }\end{array}$ & Bacterial blight & Rice plants & NK & [16] \\
\hline Sargassum wightii & $\begin{array}{l}\text { Sulphoglycerolipid } \\
\text { (methanol } \\
\text { extract) }\end{array}$ & $\begin{array}{l}\text { Xanthomonas } \\
\text { oryzae }\end{array}$ & Bacterial blight & Rice plants & NK & {$[33]$} \\
\hline Ulva fasciata & $\begin{array}{l}\text { Methanolic } \\
\text { extracts }\end{array}$ & $\begin{array}{c}\text { Xanthomonas } \\
\text { campestris, } \\
\text { Erwinia carotovora }\end{array}$ & Plant pathogens & $\begin{array}{l}\text { Various plant } \\
\text { species }\end{array}$ & NK & [34] \\
\hline $\begin{array}{l}\text { Cystoseira } \\
\text { myriophylloides, } \\
\text { Fucus spiralis }\end{array}$ & Aqueous extracts & $\begin{array}{l}\text { Agrobacterium } \\
\text { tumefaciens }\end{array}$ & Crown gall disease & $\begin{array}{c}\text { Solanum } \\
\text { lycopersicum }\end{array}$ & NK & [18] \\
\hline $\begin{array}{c}\text { Sargassum } \\
\text { latifolium, } \\
\text { Hydroclathrus } \\
\text { clathratus, Padina } \\
\text { gymnospora }\end{array}$ & $\begin{array}{l}\text { Methanolic } \\
\text { extracts }\end{array}$ & $\begin{array}{c}\text { Ralstonia } \\
\text { solanacearum, } \\
\text { Pectobacterium } \\
\text { carotovorum }\end{array}$ & Brown rot disease & Potato plants & $\begin{array}{c}\text { Induction of plant } \\
\text { defenses, } \\
\text { formation of } \\
\text { bioactive } \\
\text { secondary } \\
\text { metabolites }\end{array}$ & [35] \\
\hline $\begin{array}{c}\text { Lessonia } \\
\text { trabeculate, } \\
\text { Macrocystis } \\
\text { integrifolia }\end{array}$ & Ethanolic extracts & $\begin{array}{c}\text { Erwinia carotovora } \\
\text { Pseudomonas } \\
\text { syringae }\end{array}$ & Plant pathogens & $\begin{array}{c}\text { Various plant } \\
\text { species (tomato, } \\
\text { Arabidopsis, } \\
\text { potato plants) }\end{array}$ & NK & [17] \\
\hline $\begin{array}{l}\text { Ulva lactuca, } \\
\text { Gelidium } \\
\text { serrulatum }\end{array}$ & Alkaline extracts & $\begin{array}{l}\text { Xanthomonas } \\
\text { vesicatoria }\end{array}$ & Plant pathogen & $\begin{array}{l}\text { Tomato plants } \\
\text { (in vitro) }\end{array}$ & $\begin{array}{c}\text { Induction of plant } \\
\text { defenses }\end{array}$ & [49] \\
\hline $\begin{array}{l}\text { Ulva lactuca, } \\
\text { Sargassum } \\
\text { filipendula, } \\
\text { Gelidium } \\
\text { serrulatum }\end{array}$ & Alkaline extracts & $\begin{array}{l}\text { Xanthomonas } \\
\text { vesicatoria }\end{array}$ & Plant pathogen & $\begin{array}{l}\text { Tomato plants } \\
\text { (in vivo) }\end{array}$ & $\begin{array}{c}\text { Induction of plant } \\
\text { defenses }\end{array}$ & [49] \\
\hline $\begin{array}{l}\text { Anabaena } \\
\text { variabilis, } A . \\
\text { circinalis }\end{array}$ & $\begin{array}{l}\text { Ethyl acetate } \\
\text { extracts }\end{array}$ & Aeromonas sp. & $\begin{array}{l}\text { Skin infections, ulcers, } \\
\text { hemorrhagic and } \\
\text { septicemic infections }\end{array}$ & Fish & NK & {$[48]$} \\
\hline
\end{tabular}



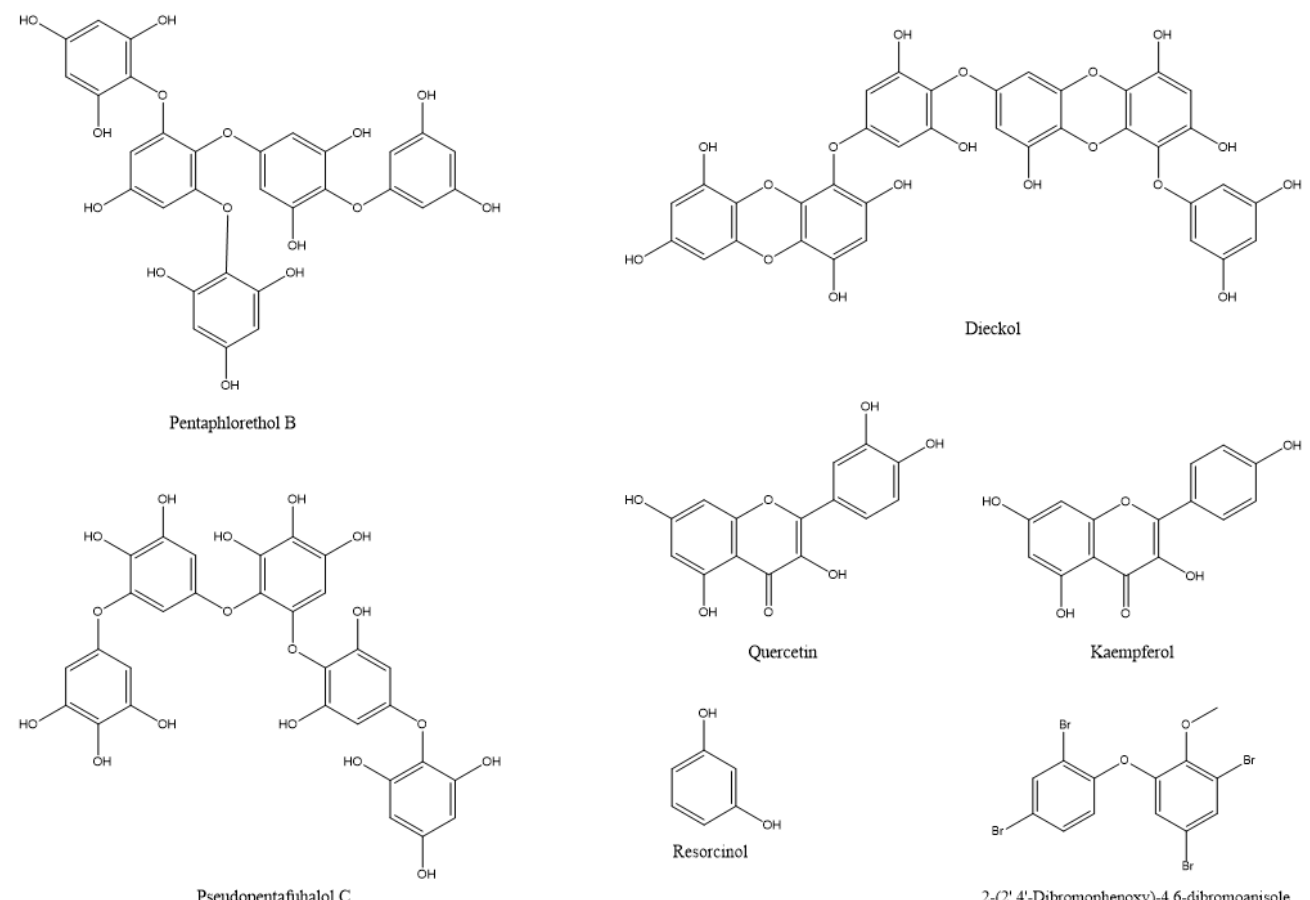

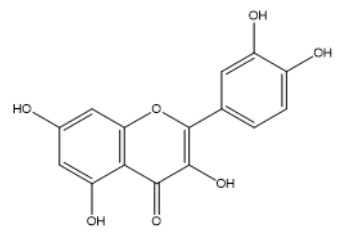

Quercetin

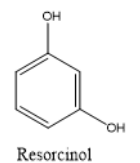

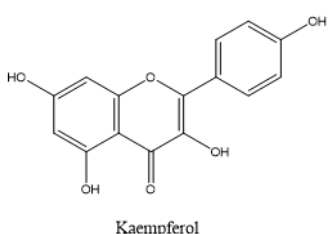

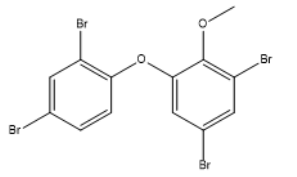

2-(2'4'-Dibromophenoxy)-4 6-dibromoanisole

Figure 2. The chemical structures of active compounds that were isolated from Cladaphora fascicularis and Arthrospira platensis and other microalgae.

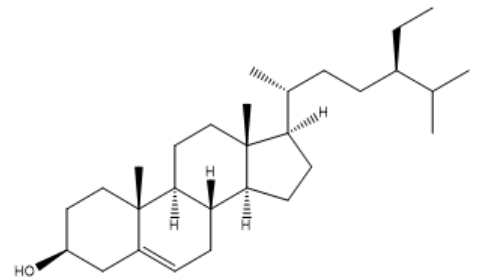

B-Sitosterol

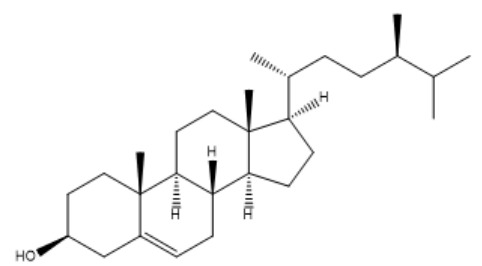

Campesterol

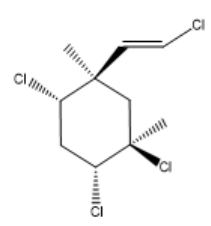

Aplysiaterpenoid A

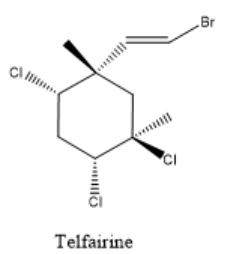

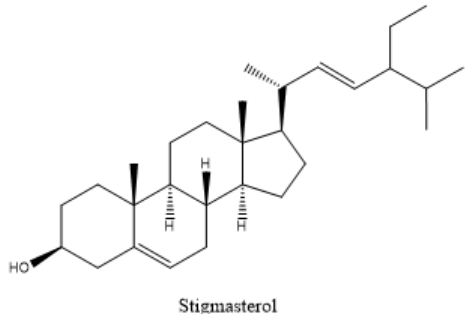

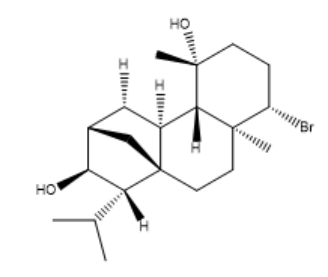

3-Hydroxy-1-deoxy-bromotetrasphaerol

Figure 3. The chemical structure of active compounds that were isolated from Sphaerococcus coronopifolius, Plocamium cartilagineum, Plocamium telfairiae, and Prasiola crispa.

\subsection{Antiviral Action}

Plant viruses are a serious threat to agricultural crops, affecting product quality and yields and resulting in severe economic losses [30]. Their management is heavily dependent on synthetic chemical products, but natural compounds are continuously gaining ground. In this respect, natural compounds from algae that exhibit antiviral properties could 
be valuable resources. Among them are various polysaccharides, such as laminarins, agarans, alginate, carrageenans, and sulphated fucans, that can function as elicitors of defense mechanisms, as well as proteins, lipids, tannins, and terpenoids $[10,13,30,50,51]$. Polysaccharides are the most common compounds in algal extracts that induces antiviral responses in plants. For example, sodium alginate (Figure 4) from marine algae exhibited strong inhibitory activity against the tobacco mosaic virus (TMV) that was isolated from systemically-infected leaves of Nicotiana tabacum L. var bright yellow [21] (Table 2).

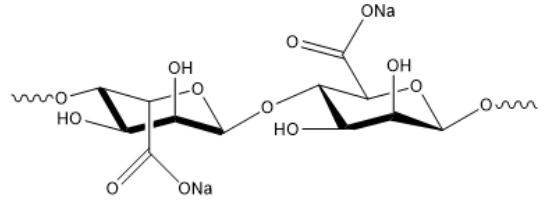

Sodium Alginate

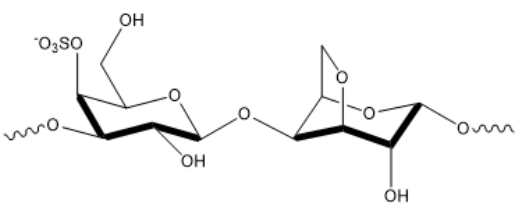

kappa-Carrageenan

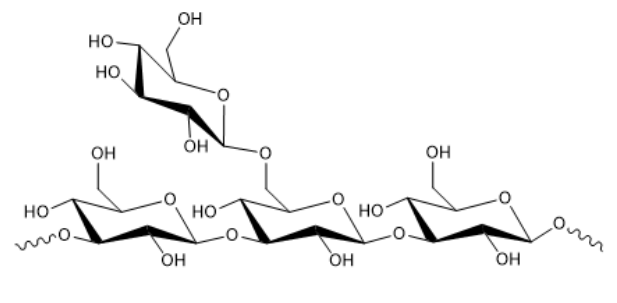

Laminarin

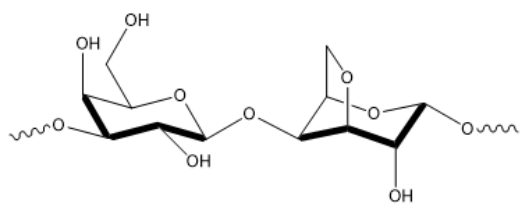

beta-Carrageenan

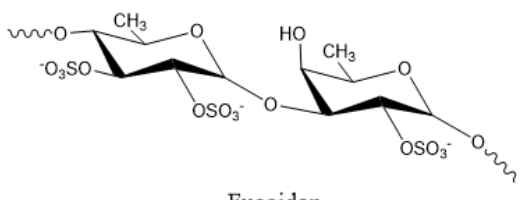

Fucoidan

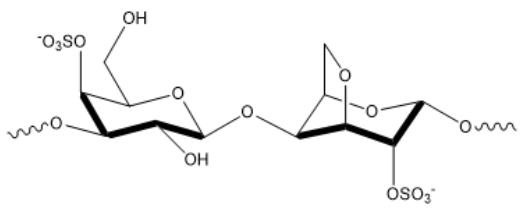

iota-Carrageenan

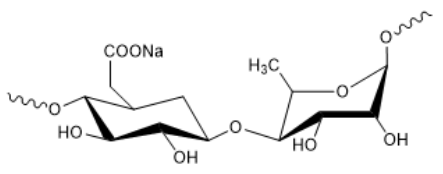

Ulvan

Figure 4. Algal polysaccharides with pesticidal action.

Table 2. Summary of the antiviral activities of algal compounds against plant pathogens.

\begin{tabular}{|c|c|c|c|c|c|c|}
\hline Algal Class/Species & $\begin{array}{l}\text { Compound/Type } \\
\text { of Extract }\end{array}$ & Target Organism & $\begin{array}{l}\text { Disease/Pathogenic } \\
\text { Phenotype }\end{array}$ & $\begin{array}{c}\text { Protected } \\
\text { Plant/Organism }\end{array}$ & Mode of Action & Reference \\
\hline $\begin{array}{c}\text { Phaeophyceae (brown } \\
\text { seaweeds) }\end{array}$ & Sodium alginate & $\begin{array}{l}\text { Tobacco mosaic } \\
\text { virus (TMV) }\end{array}$ & $\begin{array}{c}\text { Mottling and } \\
\text { discoloration on } \\
\text { leaves }\end{array}$ & Nicotiana tabacum & $\begin{array}{l}\text { Aggregation of viral } \\
\text { particles, blocking of } \\
\text { decapsulation process }\end{array}$ & {$[21]$} \\
\hline Tichocarpus crinitus & $\begin{array}{l}\text { Kappa/beta- } \\
\text { carrageenan }\end{array}$ & $\begin{array}{l}\text { Tobacco mosaic } \\
\text { virus (TMV) }\end{array}$ & $\begin{array}{c}\text { Mottling and } \\
\text { discoloration on } \\
\text { leaves }\end{array}$ & Nicotiana tabacum & $\begin{array}{c}\text { Plant tissue resistance, } \\
\text { effect on the plant } \\
\text { genome }\end{array}$ & [52] \\
\hline Tichocarpus crinitus & $\begin{array}{l}\text { Kappa/beta- } \\
\text { carrageenan }\end{array}$ & $\begin{array}{c}\text { Potato virus } \mathrm{X} \\
(\mathrm{PVX})\end{array}$ & $\begin{array}{c}\text { Crinkle } \\
\text { symptoms/plant } \\
\text { death }\end{array}$ & $\begin{array}{l}\text { Datura } \\
\text { stramonium }\end{array}$ & $\begin{array}{c}\text { Stimulation of lytic } \\
\text { processes }\end{array}$ & [22] \\
\hline $\begin{array}{c}\text { Fucus gardneri, Alaria } \\
\text { marginata, Ralfsia sp., } \\
\text { Codium fragile, } \\
\text { Fragilaria oceanica, } \\
\text { Egregia menziesii }\end{array}$ & $\begin{array}{c}\text { Methanolic } \\
\text { extract (alginate) }\end{array}$ & $\begin{array}{c}\text { Potato virus } X \\
(\text { PVX) }\end{array}$ & $\begin{array}{l}\text { Crinkle } \\
\text { symptoms/plant } \\
\text { death }\end{array}$ & $\begin{array}{l}\text { Chenopodium } \\
\text { quinoa }\end{array}$ & $\begin{array}{l}\text { Aggregation of viral } \\
\text { particles }\end{array}$ & [23] \\
\hline Ulva pertusa & Lectins & $\begin{array}{l}\text { Tobacco mosaic } \\
\text { virus (TMV) }\end{array}$ & $\begin{array}{c}\text { Mottling and } \\
\text { discoloration on } \\
\text { leaves }\end{array}$ & $\begin{array}{c}\text { Nicotiana } \\
\text { glutinosa, } \\
\text { Chenopodium } \\
\text { amaranticolor }\end{array}$ & NK & {$[53,54]$} \\
\hline
\end{tabular}


Table 2. Cont.

\begin{tabular}{|c|c|c|c|c|c|c|}
\hline Algal Class/Species & $\begin{array}{l}\text { Compound/Type } \\
\text { of Extract }\end{array}$ & Target Organism & $\begin{array}{l}\text { Disease/Pathogenic } \\
\text { Phenotype }\end{array}$ & $\begin{array}{c}\text { Protected } \\
\text { Plant/Organism }\end{array}$ & Mode of Action & Reference \\
\hline $\begin{array}{l}13 \text { species tested - } \\
\text { Cystoseira balearica, } \\
\text { Lophocladia lallemandii, } \\
\text { and Gastroclonium } \\
\text { clavatum exhibited the } \\
\text { strongest effect }\end{array}$ & Lipid extracts & $\begin{array}{l}\text { Tobacco mosaic } \\
\text { virus (TMV) }\end{array}$ & $\begin{array}{c}\text { Mottling and } \\
\text { discoloration on } \\
\text { leaves }\end{array}$ & Nicotiana tabacum & NK & [19] \\
\hline Durvillaea antarctica & $\begin{array}{l}\text { Aqueous and } \\
\text { ethanolic extracts }\end{array}$ & $\begin{array}{l}\text { Tobacco mosaic } \\
\text { virus (TMV) }\end{array}$ & $\begin{array}{l}\text { Mottling and } \\
\text { discoloration on } \\
\text { leaves }\end{array}$ & Nicotiana tabacum & NK & [17] \\
\hline $\begin{array}{l}\text { Ulva clathrata, } \\
\text { Cladosiphon } \\
\text { okamuranus }\end{array}$ & $\begin{array}{c}\text { Sulphated } \\
\text { polysaccharides }\end{array}$ & $\begin{array}{l}\text { Newcastle } \\
\text { disease virus } \\
(\mathrm{NDV})\end{array}$ & $\begin{array}{c}\text { Respiratory } \\
\text { infection, enteric } \\
\text { disease, mortality }\end{array}$ & Poultry & $\begin{array}{l}\text { Inhibition of cell-cell } \\
\text { fusion }\end{array}$ & {$[55]$} \\
\hline
\end{tabular}

NK: not known.

The degree of inhibition increased with alginate concentration and was higher when the alginate polymer had a lower mannuronate to guluronate ratio [21]. Another polysaccharide, i.e., kappa/beta-carrageenan (Figure 4) from red marine alga Tichocarpus crinitus, reduced tobacco mosaic virus (TMV) infection in Xanthi-nc tobacco leaves by 87 percent [52] The same compound stimulated lytic processes against PVX particles in the leaves of Datura stramonium [22]. Methanolic extracts from six algal species also showed inhibitory effects against PVX by more than $80 \%$. Among them, the extract from Fucus gardneri contained the polysaccharide alginate, which showed $95 \%$ success in suppressing PVX infection via aggregation of the virus particles [23].

Apart from polysaccharides, lectins (carbohydrate-binding proteins) that were isolated from the marine alga Ulva pertusa also showed antiviral action against tobacco mosaic virus (TMV) [53,54]. Similarly, lipids that were extracted from 11 algal species displayed antiviral activity against TMV on Nicotiana tabacum cv. Xanthi-nc. The brown alga Cystoseira balearica and the red alga Lophocladia lallemandii showed the highest inhibitory activity [19]. Aqueous and ethanolic extracts from the brown alga Durvillaea antarctica suppressed damage that was caused by TMV in tobacco leaves [17]. Moreover, an exciting application in livestock animals refers to the use of sulphated polysaccharides from the algae Ulva clathrata and Cladosiphon okamuranus in inhibiting Newcastle Disease Virus (NDV) infection in poultry [55].

Research for algal compounds with antiviral effects in plants has yielded significant results in the past years and remains promising for discovering new biopesticide products. However, as expected, algal antiviral research is mainly concentrated around human pathogens. Algal extracts have been studied extensively for their inhibitory action against important human viruses, such as human immunodeficiency virus (HIV), human papilloma virus (HPV), hepatitis B virus (HBV), herpes simplex virus types 1 and 2 (HSV-1, HSV-2), and diverse strains of Dengue virus (DENV-2) [56-64], suggesting that there are still many research opportunities in the field of algal antiviral products.

\subsection{Antifungal Action}

Natural algal compounds are constantly gaining ground in modern agricultural practices in controlling fungal infection, one of the most common types of disease in cultivated plants. They are mostly preferred over synthetic products, due to lower environmental impact, high specificity, and performance [14,51]. Algal powders and a large variety of extracts, such as aqueous, methanolic, ethanolic, diethyl ether, acetone, ethyl acetate, benzene, and chloroform, have proven to be effective in protecting plants against pathogenic fungal species $[17,18,20,24,35,65-77]$. For instance, ethanolic extracts of the cyanobacterium Nostoc strain ATCC 53,789 inhibited the growth of nine fungal plant pathogens (Table 3).

The extract, which was directly applied on tomato plants, completely inhibited the growth of the fungus Sclerotinia sclerotiorum [20]. The aqueous extracts of three brown 
algae Cystoseira myriophylloides, Laminaria digitata, and Fucus spiralis, that were applied as spray or drench, had a protective effect against Verticillium wilt disease that was caused by the fungus Verticillium dahliae, in greenhouse tomato seedlings [18]. In tomato leaves that were infected with Botrytis cinerea, organic extracts from the brown alga Lessonia innamomic reduced the frequency and extent of necrotic lesions, while aqueous and ethanolic extracts from the red alga Gracillaria chilensis were effective against Phytophthora innamomic, showing dose and time-dependent responses [17]. Methanolic extracts of the sea brown algae Sargassum latifolium and Padina gymnospora showed antifungal activity against phytopathogenic fungus species such as Fusarium solani and Rhizoctonia solani in addition to antibacterial activity [35]. Notably, the antifungal activity of alkaline extracts of Ulva lactuca, Sargassum filipendula, and Gelidium serrulatum has been linked to the increase in plant defense enzymes activity and the overexpression of key marker genes of plant defense pathways [49].

De Corato et al. [68] performed in vitro and in vivo tests of extracts from two brown and three red macroalgae against three phytopathogenic fungi. The compounds that were identified in the extracts included twenty fatty acids, three types of polysaccharides (laminarans, fucoidans, and alginates) (Figure 4), and three types of phlorotannins (phlorethols, fucophloretols, and eckols) (Figure 2). Regarding lipids, palmitic acid, linoleic acid, and arachidonic acid were found at the highest concentrations in most extracts. The quantity of fatty acids corresponded to most of the total dry weight of the crude extracts and could be linked to the antifungal activity [68]. Lipids that were extracted from 10 algal species inhibited the germination of Phoma tracheiphila, a pathogenic fungus that causes a disease known as Mal secco on citrus trees. More specifically, the inhibition effect of the brown alga Cystoseira balearica and the green alga Codium effusum reached 100\% [19].

Various algal oligo- or polysaccharides have demonstrated antifungal activity against plant pathogens either directly or indirectly, by activating plant defense mechanisms [78-84]. The cell wall polysaccharide laminarin (Figure 4) that was purified from the brown algae Laminaria digitata induced a defense response in grapevine leaves against the fungus Botrytis cinerea, effectively reducing the infection. In addition, grapevine plants that were sprayed on the leaves with laminarin were protected against the fungus Plasmopara viticola [85]. Polysaccharides from Anabaena sp., Ecklonia sp., and Jania sp. showed inhibitory action against Botrytis cinerea, effectively protecting strawberry fruits from infection in in vitro experiments [86]. Similar polysaccharide-rich extracts from green (Ulva lactuca and Caulerpa sertularioides) and brown (Padina gymnospora and Sargassum liebmannii) macroalgae induced resistance in tomato plants against the necrotrophic fungus Alternaria solani [87]. The water-soluble heteropolysaccharide ulvan (Figure 4) from Ulva sp. extracts significantly reduced the severity of Glomerella leaf spot (GLS) disease, caused by the fungus Colletotrichum gloeosporioides on the leaves of apple plant seedlings (Malus domestica). The induced resistance was associated with increased peroxidase activity, revealing that although ulvan does not exhibit antimicrobial activity, its action is associated with plant defense mechanisms [88].

Table 3. Antifungal activity of algal extracts against known plant pathogens.

\begin{tabular}{|c|c|c|c|c|c|c|}
\hline Algal Species & $\begin{array}{l}\text { Compound/Type } \\
\text { of Extract }\end{array}$ & Target Organism & $\begin{array}{c}\text { Disease/Pathogenic } \\
\text { Pheno- } \\
\text { type/Significance }\end{array}$ & $\begin{array}{c}\text { Protected } \\
\text { Plant/Organism }\end{array}$ & Mode of Action & Reference \\
\hline Nostoc sp. & $\begin{array}{l}\text { Ethanolic } \\
\text { extracts }\end{array}$ & $\begin{array}{c}\text { Armillaria sp., } \\
\text { Fusarium oxysporum } \mathrm{f} . \\
\text { sp. melonis, Penicillium } \\
\text { expansum, } \\
\text { Phytophthora } \\
\text { cambivora, P. } \\
\text { cinnamomi, Rhizoctonia } \\
\text { solani, Rosellinia, sp., } \\
\text { Sclerotinia sclerotiorum, } \\
\text { Verticillium albo-atrum }\end{array}$ & Plant pathogens & $\begin{array}{l}\text { In vitro (action } \\
\text { against Sclerotinia } \\
\text { sclerotiorum was } \\
\text { verified in the } \\
\text { presence of } \\
\text { tomato plant). }\end{array}$ & $\begin{array}{c}\text { Induction of plant } \\
\text { defenses }\end{array}$ & [20] \\
\hline
\end{tabular}


Table 3. Cont.

\begin{tabular}{|c|c|c|c|c|c|c|}
\hline Algal Species & $\begin{array}{l}\text { Compound/Type } \\
\text { of Extract }\end{array}$ & Target Organism & $\begin{array}{c}\text { Disease/Pathogenic } \\
\text { Pheno- } \\
\text { type/Significance }\end{array}$ & $\begin{array}{c}\text { Protected } \\
\text { Plant/Organism }\end{array}$ & Mode of Action & Reference \\
\hline $\begin{array}{c}\text { Cystoseira } \\
\text { myriophylloides, } \\
\text { Laminaria digitata, } \\
\text { Fucus spiralis }\end{array}$ & $\begin{array}{l}\text { Aqueous } \\
\text { extracts }\end{array}$ & Verticillium dahliae & Verticillium wilt disease & Tomato seedlings & $\begin{array}{c}\text { Induction of plant } \\
\text { defenses }\end{array}$ & {$[18]$} \\
\hline $\begin{array}{l}\text { Lessonia } \\
\text { trabeculata }\end{array}$ & $\begin{array}{l}\text { Ethanolic } \\
\text { extracts }\end{array}$ & Botrytis cinerea & $\begin{array}{c}\text { necrotic lesions in } \\
\text { leaves }\end{array}$ & Tomato plants & NK & [17] \\
\hline $\begin{array}{l}\text { Gracillaria } \\
\text { chilensis }\end{array}$ & $\begin{array}{l}\text { Aqueous and } \\
\text { ethanolic } \\
\text { extracts }\end{array}$ & $\begin{array}{l}\text { Phytophthora } \\
\text { cinnamomi }\end{array}$ & Plant pathogen & In vitro & NK & [17] \\
\hline $\begin{array}{c}\text { Sargassum } \\
\text { latifolium, Padina } \\
\text { gymnospora }\end{array}$ & $\begin{array}{l}\text { Methanolic } \\
\text { extracts }\end{array}$ & $\begin{array}{l}\text { Fusarium solani, } \\
\text { Rhizoctonia solani }\end{array}$ & Plant pathogens & $\begin{array}{l}\text { In vitro, in vivo } \\
(\text { Solanum } \\
\text { melongena })\end{array}$ & $\begin{array}{c}\text { Induction of plant } \\
\text { defenses, } \\
\text { formation of } \\
\text { bioactive } \\
\text { secondary } \\
\text { metabolites }\end{array}$ & {$[35]$} \\
\hline $\begin{array}{l}\text { Ulva lactuca, } \\
\text { Sargassum } \\
\text { filipendula, } \\
\text { Gelidium } \\
\text { serrulatum }\end{array}$ & $\begin{array}{l}\text { Alkaline } \\
\text { extracts }\end{array}$ & Alternaria solani & Plant pathogen & Tomato plants & $\begin{array}{c}\text { Induction of plant } \\
\text { defenses }\end{array}$ & [49] \\
\hline $\begin{array}{c}\text { Laminaria digitata, } \\
\text { Undaria } \\
\text { pinnatifida, } \\
\text { Porphyra } \\
\text { umbilicalis, } \\
\text { Eucheuma } \\
\text { denticulatum } \\
\text { Gelidium pusillum }\end{array}$ & $\begin{array}{l}\text { Fatty acids, } \\
\text { polysaccha- } \\
\text { rides, } \\
\text { phlorotannins }\end{array}$ & $\begin{array}{c}\text { Botrytis cinerea, } \\
\text { Monilinia laxa, } \\
\text { Penicillium digitatum }\end{array}$ & Postharvest pathogens & $\begin{array}{l}\text { In vitro, in vivo } \\
(\text { Fragaria } \times \\
\text { ananassa, Prunus } \\
\text { persica, Citrus } \\
\text { limon })\end{array}$ & $\begin{array}{l}\text { Direct toxicity of } \\
\text { fatty acids, } \\
\text { induction of plant } \\
\text { defenses }\end{array}$ & {$[68]$} \\
\hline $\begin{array}{l}10 \text { algal species - } \\
\text { Cystoseira } \\
\text { balearica, Codium } \\
\text { effusum and } \\
\text { Codium coralloides } \\
\text { exhibited the } \\
\text { strongest effect }\end{array}$ & Lipid extracts & Phoma tracheiphila & Mal secco disease & In vitro & NK & [19] \\
\hline Ulva fasciata & Ulvan & $\begin{array}{c}\text { Fusarium oxysporum } \mathrm{f} . \\
\text { sp. phaseoli }\end{array}$ & Bean Fusarium wilt & Phaseolus vulgaris & $\begin{array}{c}\text { Induction of plant } \\
\text { defenses, reduced } \\
\text { fungal } \\
\text { colonization in } \\
\text { plant tissues }\end{array}$ & {$[78]$} \\
\hline Ulva fasciata & Ulvan & $\begin{array}{l}\text { Colletotrichum } \\
\text { lindemuthianum }\end{array}$ & Anthracnose & Phaseolus vulgaris & $\begin{array}{c}\text { Induction of plant } \\
\text { defenses }\end{array}$ & {$[79]$} \\
\hline Ulva armoricana & $\begin{array}{l}\text { Aqueous } \\
\text { extracts (ulvan) }\end{array}$ & $\begin{array}{l}\text { Erysiphe polygoni, E. } \\
\text { necator, Sphareotheca } \\
\text { fuliginea }\end{array}$ & Plant pathogens & $\begin{array}{l}\text { Phaseolus vulgaris, } \\
\text { grapevine plants, } \\
\text { Cucumis satious }\end{array}$ & $\begin{array}{c}\text { Induction of plant } \\
\text { defenses }\end{array}$ & [80] \\
\hline Ulva fasciata & Ulvan & Blumeria graminis & Plant pathogen & $\begin{array}{l}\text { Triticum aestivum } \\
\text { cv. Kanzler, } \\
\text { Hordeum vulgare } \\
\text { cv. Villa }\end{array}$ & $\begin{array}{c}\text { Induction of plant } \\
\text { defenses }\end{array}$ & [82] \\
\hline Ulva fasciata & $\begin{array}{l}\text { Sulphated } \\
\text { polysaccha- } \\
\text { rides, alcoholic } \\
\text { extracts }\end{array}$ & $\begin{array}{l}\text { Colletotrichum } \\
\text { lindemuthianum }\end{array}$ & Anthracnose & $\begin{array}{c}\text { In vitro, Phaseolus } \\
\text { vulgaris }\end{array}$ & $\begin{array}{c}\text { Induction of plant } \\
\text { defenses }\end{array}$ & [83] \\
\hline Laminaria digitata & Laminarin & $\begin{array}{l}\text { Botrytis cinerea, } \\
\text { Plasmopara viticola }\end{array}$ & Plant pathogens & Grapevine plants & $\begin{array}{l}\text { Induction of plant } \\
\text { defenses }\end{array}$ & [85] \\
\hline $\begin{array}{l}\text { Anabaena sp., } \\
\text { Ecklonia sp., Jania } \\
\text { sp. }\end{array}$ & $\begin{array}{l}\text { Aqueous } \\
\text { extracts } \\
\text { containing } \\
\text { polysaccha- } \\
\text { rides }\end{array}$ & Botrytis cinerea & $\begin{array}{l}\text { Grey mold (postharvest } \\
\text { plant pathogen) }\end{array}$ & Strawberry plants & $\begin{array}{c}\text { Direct effect, } \\
\text { induction of plant } \\
\text { defenses }\end{array}$ & [86] \\
\hline
\end{tabular}


Table 3. Cont.

\begin{tabular}{|c|c|c|c|c|c|c|}
\hline Algal Species & $\begin{array}{l}\text { Compound/Type } \\
\text { of Extract }\end{array}$ & Target Organism & $\begin{array}{c}\text { Disease/Pathogenic } \\
\text { Pheno- } \\
\text { type/Significance }\end{array}$ & $\begin{array}{c}\text { Protected } \\
\text { Plant/Organism }\end{array}$ & Mode of Action & Reference \\
\hline $\begin{array}{c}\text { Ulva lactuca, } \\
\text { Caulerpa } \\
\text { sertularioides, } \\
\text { Padina } \\
\text { gymnospora, } \\
\text { Sargassum } \\
\text { liebmannii }\end{array}$ & $\begin{array}{l}\text { Polysaccharide- } \\
\text { rich } \\
\text { extracts }\end{array}$ & Alternaria solani & Plant pathogen & Tomato plants & $\begin{array}{l}\text { Induction of plant } \\
\text { defenses (Ulva } \\
\text { lactuca) }\end{array}$ & [87] \\
\hline Ulva sp. & Ulvan & Colletotrichumgloeosporioides & $\begin{array}{l}\text { Glomerella leaf spot } \\
\text { (GLS) disease }\end{array}$ & $\begin{array}{c}\text { Apple plant } \\
\text { seedlings (Malus } \\
\text { domestica) }\end{array}$ & $\begin{array}{c}\text { Induction of plant } \\
\text { defenses }\end{array}$ & [88] \\
\hline $\begin{array}{l}\text { Ulva fasciata } \\
\text { Enteromorpha } \\
\text { flexuosa }\end{array}$ & $\begin{array}{l}\text { Ethyl acetate, } \\
\text { benzene, } \\
\text { acetone, } \\
\text { methanolic and } \\
\text { chloroformic } \\
\text { extracts }\end{array}$ & $\begin{array}{c}\text { Macrophomina } \\
\text { phaseolina Fusarium } \\
\text { solani }\end{array}$ & Plant pathogens & Cucumber plants & NK & [89] \\
\hline $\begin{array}{l}\text { Gracilaria } \\
\text { confervoides }\end{array}$ & $\begin{array}{l}\text { Chloroformic } \\
\text { extracts }\end{array}$ & $\begin{array}{l}\text { Rhizoctonia solani, } \\
\text { Fusarium solani, } \\
\text { Macrophomina } \\
\text { phaseolina }\end{array}$ & Plant pathogens & Cucumber plants & NK & {$[75]$} \\
\hline Sargassum vulgare & $\begin{array}{l}\text { Methanolic } \\
\text { extracts }\end{array}$ & $\begin{array}{c}\text { Pythium } \\
\text { aphanidermatum }\end{array}$ & Pythium leak disease & Potato plants & NK & {$[90]$} \\
\hline Sargassum wightii & $\begin{array}{c}\text { Acetone } \\
\text { extracts (n- } \\
\text { Hexadecanoic } \\
\text { acid) }\end{array}$ & Rhizoctonia solani & Rice sheath blight & Rice plant & $\begin{array}{c}\text { Induction of plant } \\
\text { defenses }\end{array}$ & {$[91]$} \\
\hline
\end{tabular}

NK: not known.

Extracts and powders of the green seaweeds Ulva fasciata and Enteromorpha flexuosa inhibited the growth or affected the microsclerotia formation of the soil-borne fungi, Macrophomina phaseolina and Fusarium solani, that infect cucumber plants. The identification of iron-monocarbonyl and their functional groups, such as amine and ether in the extracts, could suggest a potential antifungal role for these compounds [89]. Similar compounds were also identified in the chloroform extracts from the red macroalgae Gracilaria confervoides that exhibited inhibitory action against three soil-borne pathogenic fungi of cucumber: Rhizoctonia solani, Fusarium solani, and Macrophomina phaseolina [75].

The methanolic extract of the brown alga Sargassum vulgare contained phenolic acids and flavonoids that may be responsible for the antifungal action that was observed against Pythium aphanidermatum, the causative agent of Pythium leak disease in potato [90]. Phenolic acids and phytoalexins were among the 18 compounds that were detected in the acetone extract of the brown alga Sargassum wightii. The extract exhibited antifungal activity against Rhizoctonia solani, the causative agent of rice sheath blight [91].

\subsection{Nematocidal Action}

The extracts and compounds from micro- and macroalgae are also effective against plant-parasitic nematodes that are responsible for the annual loss of $10-25 \%$ of worldwide crop production [92] (Table 4). 
Table 4. Summary of algal products and their pesticidal activity against soil nematodes.

\begin{tabular}{|c|c|c|c|c|c|}
\hline Algal Species & $\begin{array}{l}\text { Compound/Type of } \\
\text { Extract/Product }\end{array}$ & Target Organism & $\begin{array}{c}\text { Protected } \\
\text { Plant/Organism }\end{array}$ & Mode of Action & Reference \\
\hline Jania rubens & Brominated diterpenes & $\begin{array}{l}\text { Allolobophora } \\
\text { caliginosa }\end{array}$ & In vitro & NK & [93] \\
\hline Nostoc sp. & Methanolic extracts & Caenorhabditis elegans & In vitro & $\begin{array}{l}\text { Induction of plant } \\
\text { defenses }\end{array}$ & {$[20]$} \\
\hline $\begin{array}{c}\text { Spatoglossum variabile, } \\
\text { Stokeyia indica, } \\
\text { Melanothamnus } \\
\text { afaghusainii }\end{array}$ & Dry powders & Meloidogyne incognita & $\begin{array}{c}\text { Eggplant, } \\
\text { watermelon }\end{array}$ & $\begin{array}{c}\text { Direct cytotoxic } \\
\text { effect, effect on plant } \\
\text { metabolism/resistance } \\
\text { to stress }\end{array}$ & {$[65]$} \\
\hline $\begin{array}{c}\text { Spatoglossum variabile, } \\
\text { Melanothamnus } \\
\text { afaqhusainii, Halimeda tuna }\end{array}$ & $\begin{array}{l}\text { Aqueous and ethanolic } \\
\text { extracts }\end{array}$ & Meloidogyne javanica & Sunflower, tomato & $\begin{array}{l}\text { Induction of plant } \\
\text { defenses }\end{array}$ & [24] \\
\hline $\begin{array}{l}\text { Sargassum tenerrimum, S. } \\
\text { swartzii, S. wightii }\end{array}$ & $\begin{array}{c}\text { Ethanolic extracts (dry } \\
\text { powders) }\end{array}$ & Meloidogyne javanica & $\begin{array}{c}\text { Okra (Abelmoschus } \\
\text { esculentus) }\end{array}$ & NK & [94] \\
\hline $\begin{array}{l}\text { Stoechospermum } \\
\text { polypodioides }\end{array}$ & Methanolic extracts & Meloidogyne javanica & In vitro & NK & [95] \\
\hline Ecklonia maxima & $\begin{array}{c}\text { Commercial } \\
\text { formulation-Kelpak } 66 \\
\text { liquid concentrate } \\
\text { (cancelled product) }\end{array}$ & Meloidogyne incognita & $\begin{array}{l}\text { Tomato plants } \\
\text { (Lycopersicon } \\
\text { esculentum) }\end{array}$ & NK & [96] \\
\hline $\begin{array}{l}\text { Ascophyllum nodosum, } \\
\text { Ecklonia maxima }\end{array}$ & $\begin{array}{c}\text { Commercial } \\
\text { formulations-Kelpak } \\
\text { (Kelp Products Ltd., } \\
\text { Simon's Town, South } \\
\text { Africa), OSMO }{ }^{\circledR} \text { (OSMO } \\
\text { International NV, } \\
\text { Diksmuide, Belgium) }\end{array}$ & $\begin{array}{c}\text { Meloidogyne chitwoodi, } \\
\text { Meloidogyne hapla }\end{array}$ & $\begin{array}{l}\text { Tomato plants } \\
\text { (Lycopersicon } \\
\text { esculentum) }\end{array}$ & $\begin{array}{l}\text { Interrupt enzymatic } \\
\text { activities of hatching } \\
\text { process, alter sensory } \\
\text { perception of the } \\
\text { roots by the } \\
\text { nematodes }\end{array}$ & [97] \\
\hline Ascophyllum nodosum & $\begin{array}{c}\text { Commercial } \\
\text { formulation-Algaefol }^{\circledR} \\
\text { (Chema Industries, }^{\text {Egypt })}\end{array}$ & $\begin{array}{c}\text { Radopholus similis, } \\
\text { Meloidogyne incognita, } \\
\text { Belonolaimus } \\
\text { longicaudatus }\end{array}$ & $\begin{array}{l}\text { Citrus, tomato, } \\
\text { centipede grass }\end{array}$ & Cytotoxic effect & [98-101] \\
\hline
\end{tabular}

NK: not known.

Brominated diterpenes that were isolated from the marine red alga Jania rubens were effective against Allolobophora caliginosa [93]. Different concentrations of methanolic extracts from the Nostoc strain ATCC 53,789 either killed or slowed the development of the nematode C. elegans [20]. Dry powders from three macroalgae species, Spatoglossum variabile, Stokeyia indica, and Melanothamnus afaghusainii displayed a suppressive effect on the rootknot nematode Meloidogyne incognita by reducing the gall formation and preventing nematode penetration in the roots of eggplant and watermelon [65]. Similar effects against the nematode Meloidogyne javanica were identified in okra, sunflower, and tomato after treatment with aqueous and ethanolic extracts of the marine macroalgae Sargassum tenerrimum, $S$. swartzii, S. wightii, Spatoglossum variabile, Melanothamnus afaghusainii, and Halimeda tuna [24,94]. Algal extracts showed relatively similar suppressive effects with a carbofuran nematicide; however, the best result was obtained when extracts from Spatoglossum variabile were applied together with the synthetic product [24]. The marine alga Stoechospermum polypodioides was also effective against Meloidogyne javanica, causing $80 \%$ mortality, the strongest effect among 21 species of algae that were examined for their nematocidal action [95]. A reduction in root-knot nematode infestation using macroalgal extracts has been previously reported in tomato [96]. There are two commercially available products that are derived from the marine macroalgae Ascophyllum nodosum and Ecklonia maxima, that affected the hatching and sensory perception of the root-knot nematodes Meloidogyne chitwoodi and M. hapla. The alkaline extract from the brown marine alga A. nodosum showed a stronger inhibitory effect compared to the extract from the brown alga E. maxima, which in certain cases enhanced the infectivity of the nematodes [97]. Extracts of A. nodosum have shown inhibitory action 
against other nematodes, such as Radopholus similis, Meloidogyne incognita, and Belonolaimus longicaudatus, infecting citrus, tomato, and centipede grass, respectively [98-101].

\subsection{Insecticidal-Acaricidal Action of Algae}

Marine macroalgae extracts exhibit insecticidal/acaricidal activity and can be used in integrated pest management applications as environmentally friendly approaches for arthropod population control. These botanical biopesticides are safer than synthetic products and are equally or more effective since they display different modes of action. Therefore, their targets are less likely to develop resistance against them [102,103]. There are a large number of publications describing the pesticidal or repellent action of algal extracts against different arthropods that are either agricultural pests or related to human and animal health $[25,26,104-115]$. The bioactive compounds that were identified in the extracts, as expected, cover a broad range of chemical structures, including polysaccharides, phenolics, proteins, terpenes, lipids, and halogenated compounds [116]. For example, two halogenated monoterpenes (mertensene and violacene) (Figure 3) that were extracted from the red alga Plocamium cartilagineum, and the mertensene derivatives, dibromomertensene, and dihydromertensene, showed strong insecticidal activity against the tomato moth Tuta absoluta and the cereal aphid, Schizaphis graminum [104] (Table 5).

Table 5. Summary of algal products and their activity against insects and mites.

\begin{tabular}{|c|c|c|c|c|c|c|}
\hline \multirow[b]{2}{*}{ Algal Species } & \multicolumn{6}{|c|}{ Insecticidal Activity } \\
\hline & $\begin{array}{c}\text { Compound/Type of } \\
\text { Extract }\end{array}$ & Target Organism & Disease/Significance & $\begin{array}{c}\text { Protected } \\
\text { Plant/Organism }\end{array}$ & $\begin{array}{l}\text { Mode of } \\
\text { Action }\end{array}$ & Reference \\
\hline Caulerpa racemosa & $\begin{array}{c}\text { Ethanol and water } \\
\text { extracts }\end{array}$ & $\begin{array}{c}\text { Anopheles } \\
\text { stephensi, Aedes } \\
\text { aegypti, Culex } \\
\text { quinquefasciatus }\end{array}$ & Disease vectors & - & $\begin{array}{l}\text { Toxic effect } \\
\text { (larvicidal) }\end{array}$ & [25] \\
\hline $\begin{array}{l}\text { Plocamium } \\
\text { cartilagineum }\end{array}$ & $\begin{array}{c}\text { Mertensene, } \\
\text { violacene, and } \\
\text { derivatives } \\
\text { (dibromomertensene } \\
\text { and } \\
\text { dihydromertensene) }\end{array}$ & $\begin{array}{l}\text { Tuta absoluta, } \\
\text { Schizaphis } \\
\text { graminum }\end{array}$ & Crop pests & $\begin{array}{l}\text { Tomato plants, } \\
\text { cereals }\end{array}$ & $\begin{array}{l}\text { Toxic effect } \\
\text { (insecticidal, } \\
\text { reduced } \\
\text { reproduction) }\end{array}$ & [104] \\
\hline $\begin{array}{l}\text { Spirulina platensis, } \\
\text { Sargassum vulgar }\end{array}$ & $\begin{array}{l}\text { Water and ethanol } \\
\text { extracts }\end{array}$ & $\begin{array}{l}\text { Spodoptera } \\
\text { littoralis }\end{array}$ & Crop pest & $\begin{array}{l}\text { Cotton plants, } \\
\text { tomato, maize etc. }\end{array}$ & Toxic effect & [27] \\
\hline $\begin{array}{l}\text { Caulerpa sertularioides, } \\
\text { Laurencia johnstonii, } \\
\text { Sargassum horridum }\end{array}$ & Ethanol extracts & Diaphorina citri & $\begin{array}{l}\text { Citrus greening } \\
\text { disease }\end{array}$ & Citrus plants & $\begin{array}{c}\text { Toxicity, repellent } \\
\text { activity }\end{array}$ & [109] \\
\hline Ulva lactuca & $\begin{array}{l}\text { acetone, ethanol, } \\
\text { chloroform, methanol, } \\
\text { petroleum ether } \\
\text { extracts }\end{array}$ & $\begin{array}{l}\text { Culex pipiens, } \\
\text { Spodoptera } \\
\text { littoralis }\end{array}$ & $\begin{array}{l}\text { Disease vector, } \\
\text { crop pest }\end{array}$ & - & $\begin{array}{l}\text { Inhibition of } \\
\text { adult emergence } \\
\text { and larval } \\
\text { growth }\end{array}$ & [117] \\
\hline Caulerpa scalpelliformis & $\begin{array}{c}\text { Chloroform, } \\
\text { methanol, hexane } \\
\text { extracts }\end{array}$ & $\begin{array}{c}\text { Dysdercus } \\
\text { cingulatus, } \\
\text { Spodoptera litura }\end{array}$ & Crop pests & $\begin{array}{l}\text { Cotton seeds, } \\
\text { tomato, maize, } \\
\text { vegetables }\end{array}$ & Repellent activity & [118] \\
\hline Padina pavonica & $\begin{array}{c}\text { Chloroform, benzene } \\
\text { extracts }\end{array}$ & $\begin{array}{l}\text { Dysdercus } \\
\text { cingulatus }\end{array}$ & Crop pest & $\begin{array}{l}\text { Cotton, citrus, } \\
\text { maize }\end{array}$ & $\begin{array}{l}\text { Toxic effect } \\
\text { (nymphicidal, } \\
\text { ovicidal) }\end{array}$ & [115] \\
\hline Sargassum tenerrimum & $\begin{array}{c}\text { Chloroform, benzene } \\
\text { extracts }\end{array}$ & $\begin{array}{l}\text { Dysdercus } \\
\text { cingulatus }\end{array}$ & Crop pest & $\begin{array}{l}\text { Cotton, citrus, } \\
\text { maize }\end{array}$ & $\begin{array}{l}\text { Toxic effect } \\
\text { (nymphicidal, } \\
\text { oviposition } \\
\text { efficacy) }\end{array}$ & {$[114]$} \\
\hline Ulva fasciata, U. lactuca & Methanol extracts & $\begin{array}{l}\text { Dysdercus } \\
\text { cingulatus }\end{array}$ & Crop pest & $\begin{array}{l}\text { Cotton, citrus, } \\
\text { maize }\end{array}$ & $\begin{array}{c}\text { Toxic effect } \\
\text { (nymphicidal) }\end{array}$ & [105] \\
\hline Nostoc sp. & Methanol extracts & $\begin{array}{c}\text { Helicoverpa } \\
\text { armigera }\end{array}$ & Crop pest & $\begin{array}{l}\text { Cotton, tomato, } \\
\text { rice etc. }\end{array}$ & $\begin{array}{l}\text { Toxic effect } \\
\text { (larvicidal) }\end{array}$ & [20] \\
\hline
\end{tabular}


Table 5. Cont.

\begin{tabular}{|c|c|c|c|c|c|c|}
\hline \multirow[b]{2}{*}{ Algal Species } & \multicolumn{6}{|c|}{ Insecticidal Activity } \\
\hline & $\begin{array}{c}\text { Compound/Type of } \\
\text { Extract }\end{array}$ & Target Organism & Disease/Significance & $\begin{array}{c}\text { Protected } \\
\text { Plant/Organism }\end{array}$ & $\begin{array}{l}\text { Mode of } \\
\text { Action }\end{array}$ & Reference \\
\hline $\begin{array}{l}\text { Sargassum wightii, } \\
\text { Padina pavonica }\end{array}$ & $\begin{array}{l}\text { Chloroform, } \\
\text { methanol, water } \\
\text { extracts }\end{array}$ & $\begin{array}{l}\text { Dysdercus } \\
\text { cingulatus }\end{array}$ & Crop pest & $\begin{array}{l}\text { Cotton, citrus, } \\
\text { maize }\end{array}$ & $\begin{array}{c}\text { Toxic effect } \\
\text { (nymphicidal), } \\
\text { effect on } \\
\text { biophysical } \\
\text { parameters }\end{array}$ & [106] \\
\hline $\begin{array}{l}\text { Dictyota linearis, } \\
\text { Padina minor }\end{array}$ & Ethanol extracts & Aedes aegypti & Disease vector & - & $\begin{array}{l}\text { Toxic effect } \\
\text { (larvicidal) }\end{array}$ & [107] \\
\hline Caulerpa scalpelliformis & Acetone extract & Culex pipiens & Disease vector & - & $\begin{array}{l}\text { Toxic effect } \\
\text { (larvicidal) }\end{array}$ & {$[108]$} \\
\hline $\begin{array}{c}\text { Microcystis, } \\
\text { Oscillatoria, Nodularia, } \\
\text { Nostoc, Anabaena }\end{array}$ & $\begin{array}{c}\text { Hydrophilic, } \\
\text { lipophilic extracts }\end{array}$ & Aedes aegypti & Disease vector & - & Toxic effect & {$[110]$} \\
\hline Ulva lactuca & Acetone extract & $\begin{array}{l}\text { Drosophila } \\
\text { melanogaster }\end{array}$ & $\begin{array}{l}\text { Fruit fly, model } \\
\text { organism }\end{array}$ & - & Toxic effect & {$[111]$} \\
\hline \multirow[t]{2}{*}{$\begin{array}{c}\text { Chara vulgaris, } \\
\text { Parachlorella kessleri, } \\
\text { Ulva intestinalis, } \\
\text { Cladophora glomerata, } \\
\text { Nostoc carneum }\end{array}$} & Ethanol extracts & $\begin{array}{l}\text { Spodoptera } \\
\text { littoralis }\end{array}$ & Crop pest & $\begin{array}{l}\text { Cotton, tomato, } \\
\text { maize, vegetables }\end{array}$ & $\begin{array}{c}\text { Toxic effect } \\
\text { (larvicidal), effect } \\
\text { on biophysical } \\
\text { parameters }\end{array}$ & [113] \\
\hline & & & $\begin{array}{l}\text { Acaricidal } \\
\text { activity }\end{array}$ & & & \\
\hline Ascophyllum nodosum & $\begin{array}{c}\text { Commercial } \\
\text { formulation- } \\
\text { Maxicrop }{ }^{\circledR} \text { (Maxicrop } \\
\text { International Ltd.) }\end{array}$ & Tetranychus urticae & $\begin{array}{l}\text { Mottled leaves, } \\
\text { early leaf loss }\end{array}$ & Strawberry plant & - & {$[26]$} \\
\hline $\begin{array}{c}\text { Oscillatoria sp., } \\
\text { Phormidium sp., } \\
\text { Spirulina platensis, } \\
\text { Spirulina maxima, Ulva } \\
\text { intestinalis, Sargassum } \\
\text { sp., Dictyota sp. }\end{array}$ & $\begin{array}{l}\text { Methanol, } \\
\text { dichloromethane, } \\
\text { hexane extracts }\end{array}$ & $\begin{array}{c}\text { Dermatophagoides } \\
\text { pteronyssinus }\end{array}$ & Disease vector & - & Toxic effect & {$[112]$} \\
\hline
\end{tabular}

Water and ethanol extracts from the cyanobacterium Arthrospira platensis (syn. Spirulina platensis) and the brown alga Sargassum vulgar contained phenols, tannins, and alkaloids. Further analysis of phenols in A. platensis revealed the presence of the phenolic compounds: quercetin, kaempferol, and resorcinol (Figure 2), which could be related to the insecticidal action of the extracts [27]. An evaluation of the ethanolic extracts of the macroalgal species (Caulerpa sertularioides, Laurencia johnstonii, and Sargassum horridum) revealed insecticidal and repellent activities against Asian citrus psyllid adults (Diaphorina citri). The chemical composition of the three extracts showed phenols, alkaloids, terpenes, tannins, flavonoids, saponins, and anthraquinones, which are associated with insecticidal and repellent activity [109]. In certain cases, algal extracts exhibit different insecticidal effects, depending on the insect species and on the developmental stages of the target insect. For instance, the acetone extract of Ulva lactuca was the most potent extract against Culex pipiens. In the case of the cotton leafworm, Spodoptera littoralis, ethanolic and chloroform extracts acted as larvicides, methanolic and ethanolic extracts resulted in the highest pupation inhibition, whereas etheric and methanolic extracts strongly inhibited larval growth and adult emergence [117]. In terms of agricultural pests, more research has focused on the insecticidal activity of algal extracts against the cotton insect pests of the genera Dysdercus and Spodoptera. Algal extracts of various species, including Caulerpa scalpelliformis [118], Padina pavonica [115], Sargassum tenerrimum [114], Sargassum vulgar [27], Ulva fasciata, and U. lactuca [105] were effective against these agricultural pests by causing nymphal mortality, adult mortality, abnormal development, or reducing adult lifespan, fecundity, and hatchability $[14,106]$. As observed throughout the text, algal extracts could be used against more than one target 
type (antimicrobial, insect, mite, etc.). Therefore, apart from the antifungal action, the methanolic extracts of the cyanobacterium Nostoc strain ATCC 53,789 also killed larvae of the moth Helicoverpa armigera [20].

The volatile oils from Actinotrichia fragilis, Liagora ceranoides, and Colpomenia sinuosa were hydrodistilled and contained different aliphatic alcohols and long-chain hydrocarbons as the major components. They caused $55-90 \%$ and $60-80 \%$ mortality to pests of stored products Oryzaephilus mercator and Tribolium castaneum, respectively, at a dose of $12 \mu \mathrm{L} / \mathrm{L}$ air after $48 \mathrm{~h}$ of fumigation exposure [119].

The volatile oils of $A$. fragilis caused $80-90 \%$ mortality in both $T$. castaneum and O. mercator and consisted of 49\% aliphatic alcohols, mainly 1-dodecanol (39.6\%) [119]. The insecticidal activity of 1-dodecanol was suggested to be related to the developing cuticle, producing a disruption in the cuticular tanning process [120].

\subsection{Herbicidal Activity}

Natural bioherbicides have become a useful tool for the integrated management of herbaceous weeds, a major problem in agriculture that are known for impairing the growth of cultivated plants and effectively reducing crop yields [121]. Various algal metabolites, such as cyanotoxins that exhibit cytotoxicity, have been considered as potential candidates for herbicidal activity [6]. In many documented cases, cyanotoxins have ecological role as allelochemicals, inhibiting competitive macrophytes, algae, and microbes [122-125]. Such is the case in the recovery of indole alkaloid norharmane (Figure 5) from the cyanobacterium Synechocystis aquatilis, which inhibited the growth of the cyanobacteria Microcystis aeruginosa and Oscillatoria limnetica, and that of the green algae Chlorella vulgaris and Ulothrix sp. [126] (Table 6).

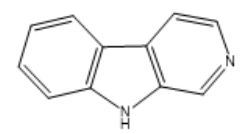

Norharmane

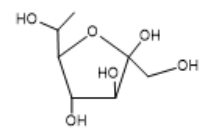

7-Deoxy-D-sedoheptulofuranose

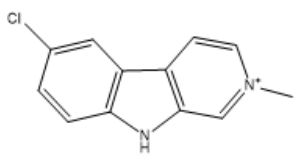

Nostocarboline

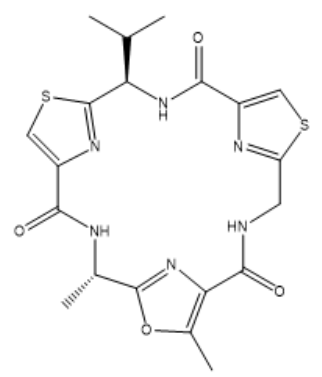

Nostocyclamide

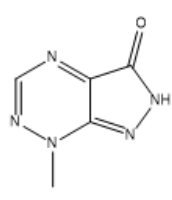

Nostocine A

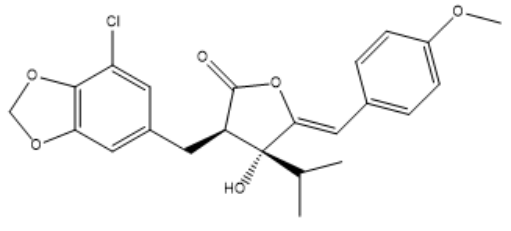

Cyanobacterin

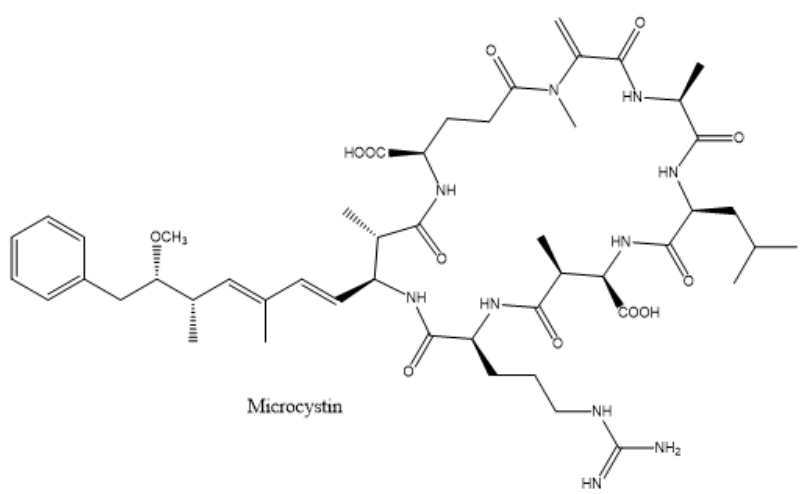

Figure 5. The chemical structures of active compounds that were isolated from Synechocystis aquatilis, Scytonema hofmanni, Nostoc sp., Microcystis aeruginosa, and Synechococcus elongatus. 
Table 6. Herbicidal activity of algal compounds.

\begin{tabular}{|c|c|c|c|c|c|}
\hline Algal Species & $\begin{array}{l}\text { Compound/Type } \\
\text { of Extract }\end{array}$ & Target Organism & Disease/Significance & Mode of Action & Reference \\
\hline $\begin{array}{c}\text { Synechocystis } \\
\text { aquatilis }\end{array}$ & Norharmane & $\begin{array}{c}\text { Microcystis aeruginosa, } \\
\text { Oscillatoria limnetica, } \\
\text { Chlorella vulgaris, } \\
\text { Ulothrix sp. }\end{array}$ & $\begin{array}{l}\text { Management of } \\
\text { algal blooms }\end{array}$ & $\begin{array}{c}\text { Effect on metabolism, } \\
\text { effect on the } \\
\text { photosynthetic } \\
\text { apparatus }\end{array}$ & [126] \\
\hline $\begin{array}{c}\text { Synechocystis } \\
\text { aquatilis, Nodularia } \\
\text { harveyana }\end{array}$ & Norharmane & $\begin{array}{c}\text { Avena fatua, Plantago } \\
\text { lanceolata, Portulaca } \\
\text { oleracea, Echinochloa } \\
\text { crusgalli, Amaranthus } \\
\text { retroflexus }\end{array}$ & Crop weeds & $\begin{array}{c}\text { Effect on metabolism, } \\
\text { effect on the } \\
\text { photosynthetic } \\
\text { apparatus }\end{array}$ & [28] \\
\hline $\begin{array}{l}\text { Schytonema } \\
\text { hofmanni }\end{array}$ & Cyanobacterin & $\begin{array}{c}\text { Lemna gibba, Setaria } \\
\text { viridis, Avena fatua, } \\
\text { Rumex crispus, } \\
\text { Polygonium convolvulus, } \\
\text { Zea mays, Pisum } \\
\text { sativum }\end{array}$ & $\begin{array}{l}\text { Management of } \\
\text { phototrophic } \\
\text { organisms }\end{array}$ & $\begin{array}{l}\text { Inhibition of } \\
\text { photosynthesis }\end{array}$ & [29] \\
\hline $\begin{array}{l}\text { Nostoc linckia, } \\
\text { Schytonema } \\
\text { hofmanni }\end{array}$ & Cyanobacterins & Synechococcus sp. & $\begin{array}{l}\text { Management of } \\
\text { algal blooms }\end{array}$ & $\begin{array}{l}\text { Inhibition of } \\
\text { photosynthesis }\end{array}$ & {$[127,128]$} \\
\hline $\begin{array}{l}\text { Nostoc sp., N. } \\
\text { spongiaeforme }\end{array}$ & $\begin{array}{l}\text { Nostocyclamide, } \\
\text { nostocine A, } \\
\text { nostocarboline }\end{array}$ & $\begin{array}{l}\text { Microcystis aeruginosa, } \\
\text { Synechococcus sp., } \\
\text { Kirchneriella contorta, } \\
\text { Chlamydomonas } \\
\text { reinhardtii, Chorella } \\
\text { pyrenoidosa, Chlorella } \\
\text { fusca, Dunaliella } \\
\text { tertiolecta, D. salina }\end{array}$ & $\begin{array}{l}\text { Management of } \\
\text { algal blooms }\end{array}$ & $\begin{array}{l}\text { Inhibition of } \\
\text { photosynthesis, } \\
\text { generation of } \\
\text { reactiveoxygen species } \\
\text { (ROS) }\end{array}$ & [129-131] \\
\hline $\begin{array}{l}\text { Microcystis } \\
\text { aeruginosa }\end{array}$ & Microcystins & $\begin{array}{c}\text { Myriophyllum } \\
\text { variifolium, Lemna } \\
\text { japonica }\end{array}$ & $\begin{array}{l}\text { Management of } \\
\text { eutrophic waters }\end{array}$ & $\begin{array}{l}\text { Inhibition of protein } \\
\text { phosphatases, cell } \\
\text { regulation }\end{array}$ & {$[132,133]$} \\
\hline $\begin{array}{l}\text { Synechococcus } \\
\text { elongatus }\end{array}$ & $\begin{array}{l}\text { 7-Deoxy- } \\
\text { sedoheptulose } \\
\text { (methanolic } \\
\text { extract) }\end{array}$ & $\begin{array}{c}\text { Anabaena variabilis, } \\
\text { Arabidopsis }\end{array}$ & $\begin{array}{l}\text { Management of } \\
\text { phototrophic } \\
\text { organisms }\end{array}$ & $\begin{array}{l}\text { Inhibition of the } \\
\text { shikimate pathway, } \\
\text { cell metabolism }\end{array}$ & [134] \\
\hline Nostoc sp. & Methanolic extract & grass seedlings & Crop weeds & $\begin{array}{c}\text { Toxicity, antimitotic } \\
\text { agents with inhibitory } \\
\text { effects }\end{array}$ & [20] \\
\hline
\end{tabular}

Although this action was not against land crop weeds but algal blooms, it has been found that norharmane can also inhibit the germination of weeds, such as Avena fatua and Plantago lanceolata; suppress the growth of Portulaca oleracea, Echinochloa crus-galli and Amaranthus retroflexus; and damage the metabolism in Arabidopsis thaliana [28]. Cyanobacterin (a chlorinated $\gamma$-lactone) (Figure 5) is another allelopathic substance that was isolated from the freshwater cyanobacterium Scytonema hofmanni that is highly toxic to other cyanobacteria and eukaryotic algae by interrupting photosynthetic electron transport [29]. There are two other structurally different cyanobacterins that were identified in Nostoc linckia that specifically inhibit electron transport in photosystem II [127,128]. A series of metabolites, such as nostocyclamide, nostocine A and nostocarboline (Figure 5) that were isolated from a Nostoc sp., exhibited toxic action against algae [129-131]. Another type of toxin, microcystins (for an example see Figure 5) that were isolated from Microcystis aeruginosa, inhibits the growth of aquatic plants, such as Myriophyllum variifolium and Lemna japonica [132,133]. A sugar, 7-deoxy-sedoheptulose (7dSh) (Figure 5) that was isolated from the cyanobacterium Synechococcus elongatus, inhibited the growth of various pho- 
totrophic organisms, including cyanobacteria as well as yeasts and plants [134]. Moreover, the methanolic extract of the Nostoc strain ATCC 53,789 hindered the development of a mixture of grass seedlings by reducing culm height and inhibiting root development, even though it did not affect the initial germination of the seeds [20]. However useful, one of the limitations of cyanobacterial toxins is their potential toxic effects against non-target organisms, including humans, animals, and plants, and their bioaccumulation in the food chain. Therefore, designing candidate agricultural products that make use of toxins should always take into consideration the adverse effects to non-target organisms [122,124].

\subsection{Plant Growth Stimulation (Biostimulators and Biofertilizers) and Bioprotection}

Algal extracts and compounds are valuable resources that display a wide range of beneficial effects on cultivated plants. Such effects include improved seed germination, plant growth, crop performance and yield, post-harvest shelf-life, and protection against biotic and abiotic factors [135-139]. Compounds with growth-stimulating activities include polysaccharides, minerals, trace elements, growth hormones, betaines, and sterols [137].

Alkaline extracts of Ascophyllum nodosum enhanced the development of the mycorrhizal fungus Rhizophagus irregularis in terms of spore germination, germ tube length, and hyphal branching. The application of the extracts improved the formation of mycorrhizal associations, increased root colonization, arbuscular maturity, and the size of greenhouse-grown Medicago truncatula plants [140]. An Ascophyllum nodosum extract significantly improved the root, shoot, and fruit biomass productivity parameters by positively influencing the rhizospheric bacterial and fungal communities that are associated with pepper and tomato plants [141]. Additionally, beneficial effects of an alkaline extract of A. nodosum were observed in tomato and sweet pepper plants. The foliar application of the extract significantly improved the plant height, leaf number, root length, dry biomass, and increased the leaf chlorophyll content under greenhouse conditions. The extract also reduced disease severity that was caused by pathogenic fungal and bacterial species by $50 \%$ under field conditions [142]. The effect of the extract was associated with the induction of plant defense-related enzymes, the production of phenolic compounds, and the activation of genes that were related to auxin, gibberellin, and cytokinin biosynthesis [142]. Plant growth regulators, such as auxin, gibberellic acid, cytokinin, and cytokinin-like compounds, have been isolated from various algal species, including A. nodosum, Ecklonia maxima, and Fucus serratus [143-146]. The application of $A$. nodosum extract on turf and forage grasses resulted in increased amounts of antioxidant compounds and activity of antioxidant enzymes, therefore, helping plants overcome oxidative stress [147].

Various Chlorella species have exhibited similar beneficial effects on the development of cultivated plants. Chlorella extracts showed a growth-promoting effect in a variety of crops, including onion, lettuce, cabbage, turnip, wheat, and maize [148-150]. A similar effect was also observed in sugar beet with the application of extracts from Chlorella vulgaris and Scenedesmus quadricauda [151]. Lettuce, tomato, and cucumber seeds that were treated with extracts of Chlorella vulgaris were characterized by enhanced germination, higher shoot, and root weights [152,153]. A combination of algal species or compounds could result in more effective microalgae-based fertilizers. For example, powders from Nannochloropsis biomass and filamentous microalgae (Ulothrix and Klebsormidium spp.) effectively enhanced tomato plant growth and improved the fruit quality [154].

Apart from eukaryotic algae, cyanobacteria have also been identified as effective plant biofertilizers. In this respect, composts that were amended with Anabaena variabilis and A. laxa resulted in enhanced soil organic carbon, nitrogen fixation, significant improvement in growth, yield, fruit quality parameters, nitrogen, phosphorus, and zinc content [73]. Anabaena variabilis and a Nostoc sp. increased seed germination, plant height, leaf length, and grain yield, when they were applied as biofertilizers on rice seeds or plants $[155,156]$. Treatment with Anabaena laxa resulted in $25 \%$ enhanced germination in cumin, while Calothrix elenkinii enhanced the root and shoot length significantly in cumin, fennel, and coriander [157]. Filtrates of Calothrix ghosei, a Nostoc sp. and Hapalosiphon intricatus, 
enhanced the germination, radicle, and coleoptile length in experiments with wheat seeds. Analysis of the filtrates revealed the presence of several amino acids, such as histidine, and auxin-like compounds [158]. The foliar application of seaweed extracts of Macrocystis pyrifera, Bryothamnion triquetrum, Ascophyllum nodosum, Grammatophora spp., and Macrocystis integrifolia improved the quality of cucumber fruits by increasing the antioxidant capacity of the plant [159]. Moreover, supplementation with Arthrospira platensis (Spirulina platensis) biomass enhanced the plant growth and improved the seed germination of leafy vegetables, including Eruca sativa, Ameranthus gangeticus, Brassica oleracea, and Brassica rapa [160].

The utilization of algal substances could also provide significant benefits to crops in overcoming various types of abiotic stress. Extracts of the brown macroalga Ascophyllum nodosum significantly increased the tolerance of Arabidopsis thaliana to freezing temperatures, both in vitro and in vivo. The effect was also characterized by reduced tissue, membrane, and chlorophyll damage. Tolerance to freezing stress was also observed when plants were treated only with the lipophilic fraction of the extracts, suggesting that the effect could be associated with its components [161]. Moreover, the extract of Ascophyllum nodosum improved the fresh and dry weight of shoots and roots of Zea mays that were grown in phosphorous-limited conditions [162]. Vitis vinifera plants that were treated with algal extracts exhibited high tolerance against water stress. The extract significantly enhanced potassium and calcium fluxes, improved plant growth, and the accumulated macronutrients in the plant organs [163].

Similarly, Chlorella vulgaris induced tolerance against water stress in Vicia faba plants [164]. Extracellular products of the cyanobacterium Scytonema hofmanni counteracted the effects of salt stress in rice plants. Contrary to salt-stressed plants, treated plants had a higher shoot weight and length, carotenoid content, root weight, and total free porphyrin [165]. A similar effect was induced by Dunaliella salina exopolysaccharides, which alleviated the salt stress on tomato plants. The treated plants were also characterized by higher length and weight of their shoot and root systems, higher $\mathrm{K}^{+}$concentration, and $\mathrm{K}^{+} / \mathrm{Na}^{+}$ratio [166]. Treating water-stressed whole grains of wheat plants with water extracts of Chlorella ellipsoida and Spirulina maxima resulted in increased total carotenoid, tocopherol, phenolic, and protein contents [167]. Algal extracts are also effective in activating mechanisms that protect plants from oxidative stress, which is caused by the accumulation of reactive oxygen species (ROS), such as the superoxide anion $\left(\mathrm{O}^{-}{ }_{2}\right.$. $)$ and hydrogen peroxide $\left(\mathrm{H}_{2} \mathrm{O}_{2}\right)$. This response is mainly associated with antioxidant compounds, such as carotenoids, cytokinins, $\alpha-$ tocopherol, and ascorbic acid, as well as the activation of enzymes with antioxidant activity, including peroxidase, superoxide dismutase, glutathione reductase, catalase, and ascorbate peroxidase $[14,137,138,147,164,166,168]$.

\section{Mechanism of Action of Algal Metabolites}

The mechanisms of action of the majority of algal metabolites against agricultural pests are not known, and mechanism studies are usually performed against medically important organisms [169]. However, the available information on potentially biopesticidal algal metabolites is presented below.

\subsection{Inhibition of Photosynthesis}

Research on allelopathy between different algal species/genera has led to the discovery of novel secondary metabolites with various modes of action [170]. Among them, photosynthesis inhibitors can potentially be used in higher plants, due to the similarity of photosynthetic apparatus between algae and plants. One of the first photosynthesis inhibitors was isolated from the cyanobacterium Scytonema hofmanni UTEX B 2349. Cell extracts or spent medium of this cyanobacterium inhibited the growth of other cyanobacteria and green algae [171]. This led to the isolation of a halogenated secondary metabolite called cyanobacterin (Figure 5) [171]. Cyanobacterin was ineffective against all eukaryotic algae and eubacteria [171,172]. Further work demonstrated thylakoid damage in transmission electron micrographs of Synechococcus sp. ATCC 27,146 cells that were exposed 
to the minimum effective dose of $4.6 \mu \mathrm{M}$ cyanobacterin. Cyanobacterin also inhibited light-dependent oxygen evolution in the same cyanobacterium, suggesting specific action on photosynthetic electron transport [172]. Cyanobacterin was toxic to aquatic Lemna species and terrestrial angiosperms [29]. Similar to Synechococcus sp. ATCC 27146, photosynthetic electron transport was inhibited by cyanobacterin in purified pea chloroplasts. Both cyanobacteria and plant studies suggested that the potential site of action of cyanobacterin was a site in PSII (Figure 6) [29]. The site of action proved to be different from the site of action of 3-(3,4-dichlorophenyl)-1,1-dimethylurea (DCMU), which is the quinone binding protein $\left(\mathrm{Q}_{\mathrm{B}}\right)$ of PSII [173]. Cyanobacterin did not have any effect on PSI activity [29]. A cyanobacterin-resistant strain of the cyanobacterium Anacystis nidulans R2 was selected through mutagenesis with nitrosoguanidine. The mutant was not resistant to 3-(3,4dichlorophenyl)-1,1-dimethylurea, or DCMU and the authors concluded that cyanobacterin inhibited electron flow from quinone-A to quinone-B [174]. The toxicity of cyanobacterin to non-target organisms was studied in Daphnia magna. $\mathrm{LC}_{50}$ (48-h) of cyanobacterin in D. magna and was approximately $1.37 \mu \mathrm{g} \mathrm{mL}^{-1}$, suggesting caution if this metabolite would ever be used as a herbicide [175].

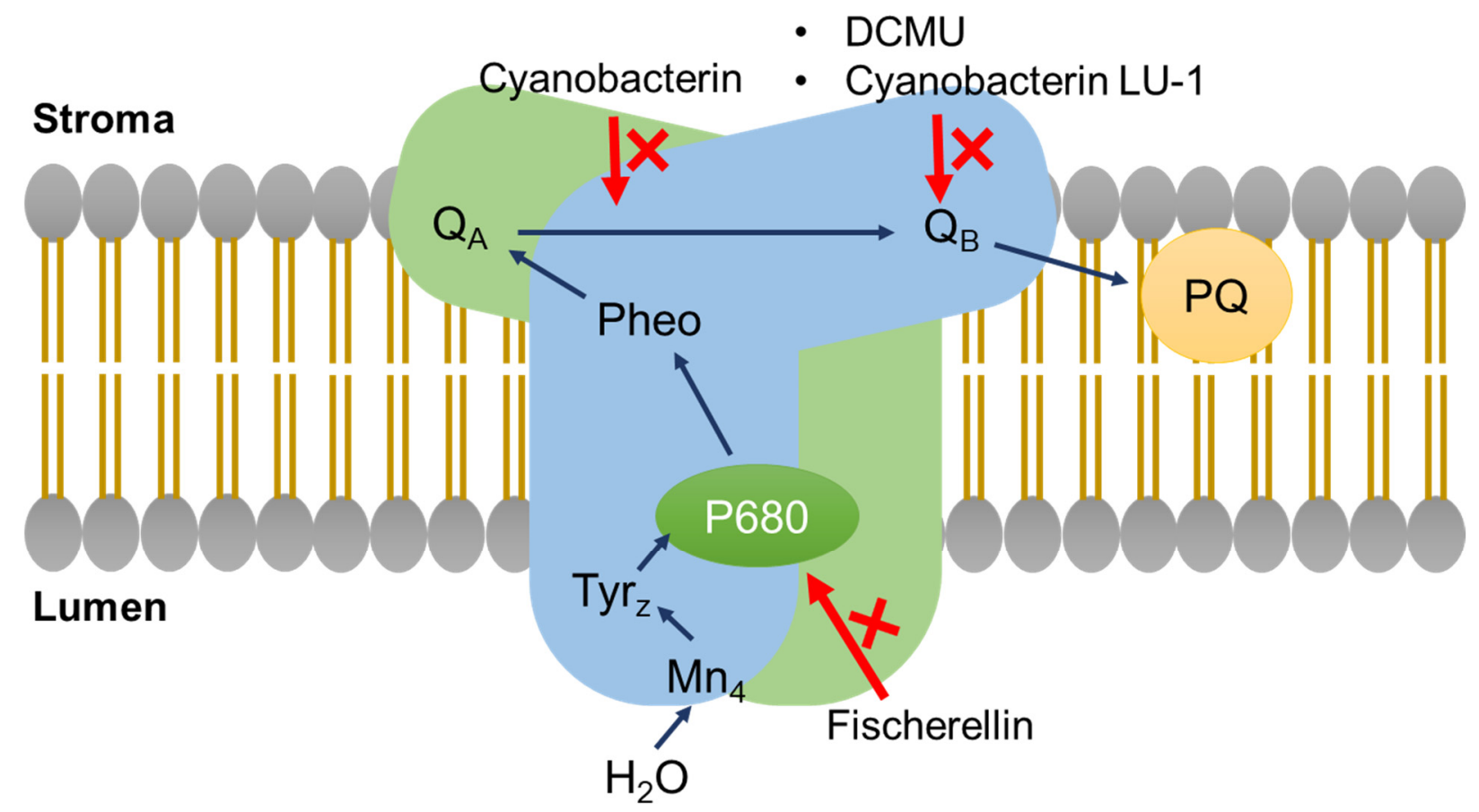

Figure 6. The mode of action of photosynthesis inhibitors as shown on a simplified diagram of photosystem II within the thylakoid membrane. $\mathrm{QA}=$ primary quinone acceptor; $\mathrm{QB}=$ secondary quinone acceptor; $\mathrm{PQ}$ = plastoquinone; $\mathrm{Pheo}=$ pheophytin; $\mathrm{P} 680$ = photosystem II primary donor; TyrZ $=$ tyrosine $-Z$ radical.

A secondary metabolite, named cyanobacterin LU-1, that was isolated from Nostoc linckia CALU 892, also inhibited the growth of cyanobacteria and algae (Figure 6). This metabolite inhibited the $\mathrm{O}_{2}$ evolution in Synechococcus sp. PCC 7942 cells in a lightdependent manner. However, its structure and site of action seems to be different compared to cyanobacterin from Scytonema hofmanni. Mutants of Synechococcus sp. PCC 7942 and Anabaena variabilis ALU 458 that were resistant to cyanobacterin LU-1 were also resistant to DCMU, suggesting binding to quinone-B by cyanobacterin LU-1. This metabolite $(5 \mathrm{mg})$ was non-toxic to mice by intraperitoneal injection [127].

The spent culture medium and the cell-free extract of an Oscillatoria strain that was isolated from a lake in India inhibited the growth of several cyanobacteria and algae. Ether extract of this strain inhibited oxygenic photosynthesis in Anacystis nidulans [176], and the growth of angiosperm plants, presumably through inhibition of electron transport at a site 
that was different than those of cyanobacterin and DCMU [177]. The cell-free extracts were non-toxic to mice. The active metabolites in ether extract seemed to consist of saturated fatty acids [177].

Nostocarboline (Figure 5) from Nostoc 78-12A is a $\beta$-carboline alkaloid inhibiting cholinesterase [178]. Nostocarboline and its derivatives inhibit the growth of cyanobacteria and green algae. The inhibitory activity seemed to be related to the inhibition of photosynthesis in cyanobacteria, since this alkaloid was not active against non-photosynthetic bacteria [129]. Further work proved nostocarboline to be a mammalian serine protease inhibitor. Therefore, photosynthetic inhibition in cyanobacteria and algae by nostocarboline might be related to the inhibition of serine proteases in cyanobacteria and algae [179].

Fischerellin A (Figure 1) was isolated from the cyanobacterium Fischerella muscicola UTEX 1829, which inhibited the growth of cyanobacteria and green algae. It did not affect the growth of bacteria. Fischerellin specifically inhibited the photosynthetic electron transport involving PSII in the cyanobacterium Anabaena sp. P9 (Figure 1) [180] and in the aquatic macrophyte Lemna minor [181]. Later, Srivasatava et al. [182] demonstrated that fischerellin inactivated the reaction centre of PSII and modified the PSII antenna architecture. Apart from its herbicidal effect, fischerellin effectively inhibited the growth of the fungi/oomycetes Uromyces appendiculatus, Erysiphe graminis, Phytophthora infestans, and Pyricularia oryzae [181].

\subsection{Induction of Plant Defense Responses}

Exposure to pathogens triggers several defense-related pathways in plants. This is achieved through signal molecules called elicitors that are recognized by receptors on the plant cell membrane [183]. Elicitors may originate from the pathogen or from the plant itself $[67,85]$, or they may be a molecule from a non-pathogenic unrelated organism [183].

The principal cell wall polysaccharides from marine macroalgae, ulvans, alginates, fucans, laminarin, and carrageenans, can activate defense mechanisms in plants against pathogens (Figure 7). This response is mainly associated with the generation of oxidative burst and the activation of the salicylic acid (SA), ethylene, and jasmonic acid (JA) signalling pathways [50].

Therefore, this property allows algae and their compounds to be used as plant protectants [184]. One advantage of algal elicitors is that, contrary to pathogens, they don't usually induce cell death in plants [85]. One notable example is carrageenans (Figure 4) that are found in the cell wall of red algae. Mercier et al. [185] compared the elicitor responses of the pathogen oomycete Phytophthora parasitica var. nicotianae and, $\mathrm{K}_{-}, \mathrm{l}-$, and $\lambda$-carrageenans in tobacco plants. After infiltration into the mesophyll layer of tobacco leaves, the pathogen caused desiccation and necrosis in the infiltrated area in $24 \mathrm{~h}$. Enzymes that are involved in defense pathways, including sesquiterpene cyclase, chitinase, and proteinase inhibitor type II, were induced, but the activities usually disappeared in $24 \mathrm{~h}$. JA, ethylene, and SA pathways were activated in plants by the pathogen. After the application of $\lambda$-carrageenan, macroscopic changes that were similar to the ones that are induced by the pathogen were observed. However, complete necrosis was not recorded. Among the defense genes, sesquiterpene cyclase, chitinase, and proteinase inhibitor type II were induced in plants, and high transcript abundance continued for at least a week for the latter two genes. Similar to the pathogen, JA, ethylene, and SA pathways were activated in plants, albeit for longer durations [185]. The same authors suggested that the perception of algal polysaccharides might be initiated by receptors on the plasma membrane.

Similarly, Sangha et al. [186] investigated the effects of $l$ - and $\lambda$-carrageenans on the induction of defense responses in Arabidopsis thaliana ecotype Col- 0 against the phytopathogenic fungus Sclerotinia sclerotiorum. While $\lambda$-carrageenan-treated plants were resistant to infection, the ones that were treated with l-carrageenan were susceptible. JA pathway-related genes were induced in the former. Additionally, increased oxalase and oxidase activity were detected in plants that were treated with $\lambda$-carrageenan, offsetting the 
oxalic acid that is secreted by the fungus for infection. The authors attributed the different responses of the plant to $l$ - and $\lambda$-carrageenans and to the higher sulfation in the latter [186].

Laminarin, a linear $\beta-1,3$ glucan (Figure 4) is a long-term storage compound in brown algae [187]. Incubation of tobacco cv BY cells with laminarin triggered multi-step defense responses, including rapid alkalinization of the culture medium and $\mathrm{H}_{2} \mathrm{O}_{2}$ release, induction of the phenylpropanoid pathway that was demonstrated by a strong Phe ammonia-lyase (PAL) activity at $4 \mathrm{~h}$, caffeic acid $\mathrm{O}$-methyltransferase up-regulation at $2 \mathrm{~h}$ until $25 \mathrm{~h}$, and a strong increase in SA from $6 \mathrm{~h}$ to $48 \mathrm{~h}$. Similarly, the fatty acid pathway was induced, as demonstrated by lipoxygenase (LOX) activity that was induced within four hours of incubation with laminarin. On the other hand, infiltration of tobacco cv Samsun NN plants with laminarin resulted in the induction of four families of pathogenesis-related (PR) proteins (PR1, PR2, PR3, and PR5), which have antimicrobial activities. All these defense reactions protected the tobacco leaves against infection by the bacterium Erwinia carotovora subsp. carotovora, which causes soft rot disease [188]. Similarly, laminarin induced defense responses in grapevine (Vitis vinifera L.), which included $\mathrm{H}_{2} \mathrm{O}_{2}$ release, calcium uptake, alkalinization of the culture medium, and induction of mitogen-activated protein kinases. The defense responses in the grapevine also included the upregulation of defense-related genes, such as 9-lipoxygenase (Lox) and glutathione-S-transferase (Gst), phenylalanine ammonia lyase $(\mathrm{Pal})$, stilbene synthase 1 (Sts1), polygalacturonase-inhibiting protein (Pgip), basic class I, acidic class III, and acidic class IV chitinase genes, class I $\beta$-1,3-glucanases gene Glu1, and serine protease (Pin) genes. Laminarin also caused the production of antimicrobial phytoalexins in the grapevine. These defense reactions protected grapevine against Botrytis cinerea and Plasmopara viticola infections [85].

The presence of $\beta-1,3$-glucans in the unicellular eukaryotic members of Bacillariopyhta and Chryosophyceae, and in Nannochloropsis gaditana of Eustigmatophyceae $[189,190]$ opens new avenues of research for their effects in plant defense metabolism. It also provides an opportunity to mass culture these microalgae, preferably within a biorefinery approach, where $\beta$-1,3-glucan-separated biomass can be used for other purposes (e.g., feed supplement, pigment source, biofuel feedstock).

An extract of Ulva spp. was tested as an elicitor in Medicago truncatula. After the application of Ulva extract, the expression patterns of mainly defense-related genes were undertaken using a macroarray. In addition to the aforementioned defense-related genes, the upregulation of genes for the cell wall proteins calmodulin, ribonuclease, and aquaporin was observed. Genes that were involved in carbon and nitrogen metabolism were not downregulated, suggesting that the induction of defense genes did not affect primary metabolism. The Ulva extract protected M. truncatula against the fungal pathogen Colletotrichum trifolii, which causes anthracnose disease [67].

Tobacco leaves that were treated with sulphated fucans (Figure 4) exhibited defensive responses against the tobacco mosaic virus. The oligofucans, in this case, also stimulated the SA pathway and the expression of pathogenesis-related proteins [191].

During a fungal infection, some plant species recognize the chitin (poly- $(1 \rightarrow 4)-\beta$ linked N-acetyl-D-glucosamine) components in fungal cell walls and induce lignification as a defense mechanism to prevent further fungal damage. This was initially demonstrated in wounded wheat leaves when crab and fungal chitin, chitosan, and ethylene glycol chitin were applied as elicitors [192]. Later work demonstrated the induction of chitinase in melon seedlings upon treatment with varying concentrations of chitin oligosaccharides. The same study suggested the hexamer or heptamer chitin oligomer as the optimal size for maximum chitinase activity [193]. Kaku et al. [194] identified a high-affinity binding protein for chitin in the plasma membrane of rice cells. The knockdown of the receptor gene by RNA interference shut down the chitin-induced defense responses. Further work demonstrated that, in addition to this membrane receptor glycoprotein, a receptor kinase was also required for chitin-based elicitor response in rice [195].

Chitin is naturally found in the exoskeletons of crustaceans and the cell walls of fungi. Industrial production of chitin utilizes crustaceans, such as crabs and shrimp. The isolation 
of chitin from these sources is a lengthy process, including treatment with $\mathrm{HCl}$ and then with $\mathrm{NaOH}$, increasing the cost of production [196]. Less known is the presence of chitin in some algal groups, such as green algae and diatoms [197]. Especially some diatom species from the Cyclotella and Thallassiosira genera synthesize chitin as nanofibers and extrude through pores on the frustule. The extruded chitin nanofiber is in the form of $\beta$-chitin, which is easier to dissolve and modify compared to $\alpha$-chitin [198]. Moreover, extruded chitin can be readily isolated from the culture medium.

Within a biorefinery approach, a diatom biomass can be produced to obtain various valuable chemicals, including lipids and chitin [199]. The leftover diatom frustules will also have the potential to be used as an insecticide. Diatomaceous earth (DE) is formed from fossilized diatoms dating back 20 to 80 million years. DE contains about $50 \%$ moisture and up to $94 \%$ silica of dry weight. After mining, the moisture is reduced, and the DE is milled to reduce the particle size to between 10-50 $\mu \mathrm{m}$. DE is safe for humans, and among many uses, it is also an effective insecticide. After application, DE dust is picked up by insect bodies, where DE damages the wax coat of insects. This results in water loss from the body of insects, causing desiccation and death [200]. Therefore, leftover diatom frustules would be a valuable side product, where all components of diatom biomass can be utilized.

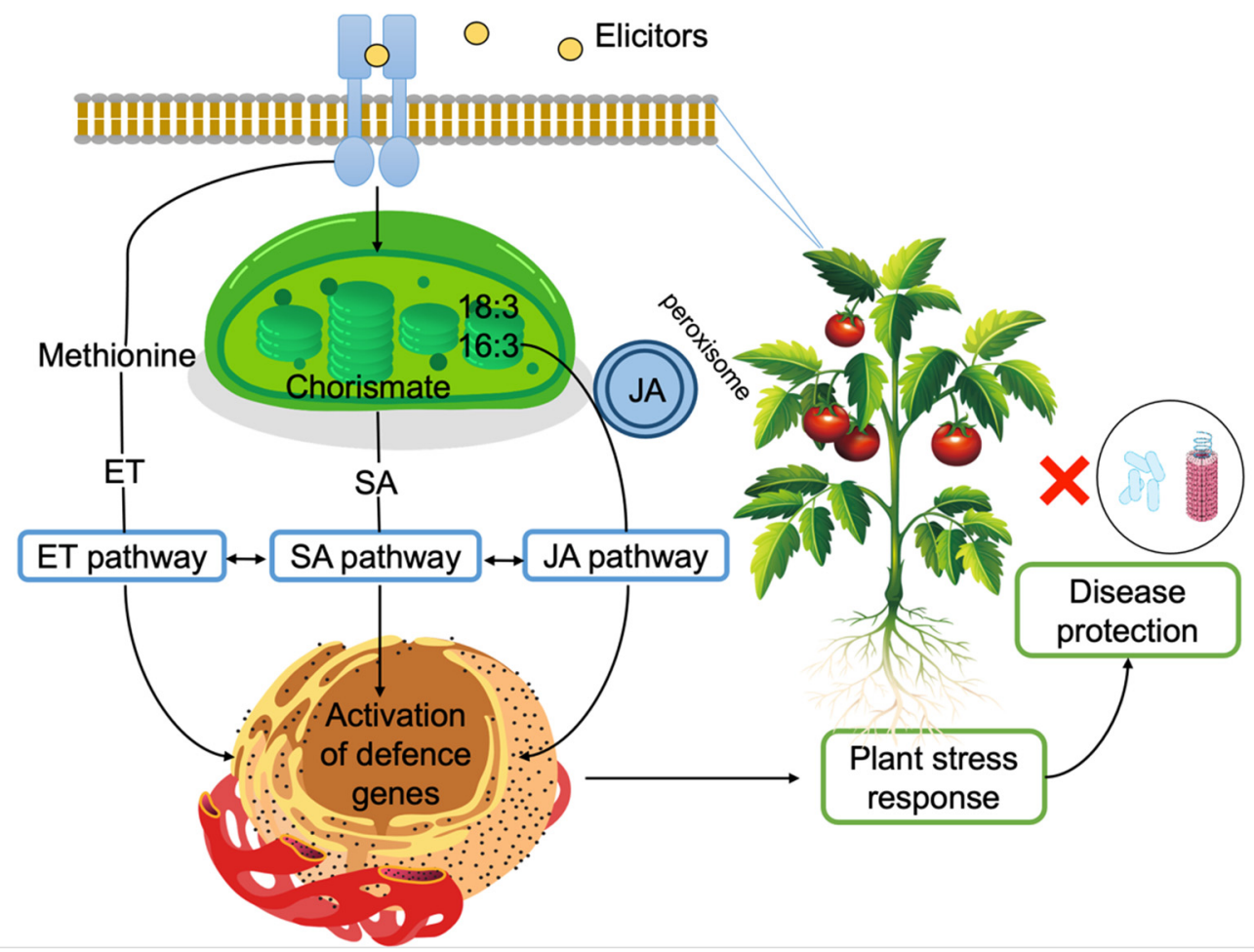

Figure 7. Induction of plant defense responses via elicitors. Elicitors are recognized on the plasma membrane. Jasmonic acid (JA) biosynthesis starts with $\alpha$-linolenic acid (18:3) or hexadecatrienoic acid (16:3) in the chloroplast. Conversion to JA takes place in the peroxisome [201]. Salicylic acid (SA) biosynthesis starts with chorismate in the chloroplast and SA is transported into the cytosol [202]. Ethylene (ET) biosynthesis starts with methionine and ET is recognized by receptors on the endoplasmic reticulum. All three pathways eventually lead to defense gene expression and evidence suggest crosstalk between these pathways [203].

\subsection{Inhibition of Quorum Sensing}

Although algal extracts or metabolites exert antimicrobial properties, knowledge on the mechanism of action of these substrates against plant pathogens is limited. A notable example is the production of halogenated furanones by the red alga Delisea pulchra. Early investigations revealed that D. Pulchra produced secondary metabolites that prevented fouling on its surface [204]. These secondary metabolites, namely halogenated furanones, 
were proposed to biomimic acylated homoserine lactones (AHLs) [205], which are signalling molecules that are involved in quorum sensing for the colonization of Gram-negative bacteria [206]. This led Manefield et al. [207] to test a synthetic halogenated furanone for the inhibition of N-3-oxohexanoyl-L-homoserine lactone (3-oxo-C6-HSL) in the plant pathogen Erwinia carotovora subsp. carotovora. Its metabolite 3-oxo-C6-HSL regulated the production of extracellular degradative enzymes and a carbapenem antibiotic, where both processes help the bacterium to infect terrestrial plants [207]. The results suggested that the halogenated furanone inhibited carbapenem production and reduced the production of extracellular enzymes, the exact mechanisms of which were not clear. Other work demonstrated that D. pulchra furanones might displace AHL from its binding site, which is a transcriptional activator (i.e., Lux R protein) [208,209]. Follow-up work by Manefield et al. [210] failed to detect furanone binding to the LuxR protein that is expressed in E. coli. Instead, their results showed decreased concentrations of cytoplasmic LuxR protein when furanone is added, which led them to suggest halogenated furanones interacted with LuxR causing conformational change for rapid degradation.

Quorum sensing inhibitors were also detected in the microalgae Chlamydomonas reinhardtii 2137 [211], Chlorella saccharophila CCAP211/48 [212], and the cyanobacterium Lyngbya majuscula $[213,214]$. Therefore, both macro- and microalgae (including cyanobacteria) are unique and largely untapped resources for discovering quorum sensing inhibitors.

\subsection{Neurotoxicity}

Although there is a lack of information regarding the mechanism of action of algal metabolites against agricultural pest insects, limited work that was performed with other insects might provide some clues. Watanabe et al. [215] reported the insecticidal activities of two halogenated monoterpenes, aplysiaterpenoid A and telfairine (Figure 3), from the red alga Plocamium telfairiae. Aplysiaterpernoid A and telfairine caused $60 \%$ and $80 \%$ mortality in the German cockroach (Blatella germanica), respectively. Telfairine also caused random firings in the central nervous system, similar to the effects of (1246/35)$1,2,3,4,5,6$-hexachlorohexane $(\gamma$-BHC), an organochlorine insecticide. Their modelling studies suggested that both aplysiaterpenoid A and telfairine might act on the picrotoxinin receptors of insects.

Extracts of the macroalga Prasiola crispa were shown to possess insecticidal properties in fruit fly (Drosophila melanogaster) and cockroach (Nauphoeta cinerea) [216]. In a follow-up study, Prasiola crispa extracts and its phytosterols, namely $\beta$-sitosterol, campesterol and stigmasterol (Figure 3), exhibited insecticidal activities in the cockroach Nauphoeta cinerea [217]. To understand the mechanism of action of the extracts and isolated compounds, the authors performed acetylcholinesterase activity assays, semi-isolated heart preparations to determine heartbeats, grooming activity assays, and cockroach neuromuscular function assays. The cockroach brain preparations did not reveal any acetylcholinesterase activity. However, the algal extract caused a significant and reversible drop in the heartbeats in the cockroach semi-isolated heart preparations and a significant change in the grooming activity. The extracts and the aforementioned phytosterols also caused neuromuscular inhibition, which was reduced by the application of phentolamine, an octopamine receptor inhibitor. Altogether, these results suggested the involvement of octopaminergic-cholinergic pathways in the insecticidal activity of this Antarctic macroalga [217].

\subsection{Production of Antimetabolites}

An antimetabolite may bind to an enzyme as the native substrate does; however, it is not converted to a functional product. Therefore, antimetabolites may compete with the natural substrates and may block an enzyme's catalytic activity. Brilisauer et al. [134] observed growth inhibition of the cyanobacterium Anabaena variabilis ATCC 29,413 by the spent culture media of the cyanobacterium Synechococcus elongatus PCC 7942. The isolation and chemical characterization of the extracellular inhibitory compounds proved the presence of 7-deoxysedoheptulose (7dSh) (Figure 5). Incubation of A. variabilis with puri- 
fied 7dSh resulted in the accumulation of 3-deoxy-D-arabino-heptulosonate 7-phosphate (DAHP) in cells, which is the natural substrate of 3-dehydroquinate (DHQ) synthase. The results suggested that $7 \mathrm{dSh}$ was the antimetabolite of DAHP, the native substrate of the DHQ synthase in the shikimate biosynthesis pathway [134,218]. Accordingly, the inhibition of this pathway disturbed protein synthesis by inhibiting aromatic amino acid biosynthesis [134]. The shikimate pathway occurs in bacteria, fungi, and plants, but not in animals [219]. As expected, 7dSh inhibited the growth of Saccharomyces cerevisiae and Arabidopsis thaliana. No cytotoxicity was detected in mammalian cells, potentially making 7dSh an ideal antibacterial, antifungal, or herbicidal compound.

\subsection{Blocking Virus Entry into the Plant}

Sodium alginate (Figure 4 ) is a commercial gelling product that is obtained from brown seaweeds [220]. Sano et al. [21] investigated the inhibitory activity of alginate on the infection of tobacco leaves with tobacco mosaic virus (TMV). This polysaccharide did not inactivate TMV. However, its application on leaves reduced TMV infectivity, with the reduction being proportional to the salginate concentration and stiffness of the polysaccharide. The addition of sodium alginate caused TMV particles to form large aggregates on the cell surface, blocking TMV RNA entry into the plant cells. The authors also suggested that anions of the polysaccharide might have interacted with the cationic amino groups of $\mathrm{TMV}$, preventing interaction with the anionic phosphate groups of the cell membrane.

\section{Conclusions}

Extensive research in the past decades on macro- and microalgal species has resulted in the discovery of an impressive array of extracts and bioactive compounds with pesticidal action for application in agricultural practices. These compounds have been used effectively as standalone treatment against agricultural pests, but their full potential can be revealed by combining them with other techniques in the context of integrated pest management. Moreover, even though a lot of progress has been recorded so far in deciphering their mode of action, more knowledge is expected to be produced in the future in this regard. Conservative estimates suggest the number of current algal species to be over 70,000 [221]. Yet, only a small number of these species have been investigated for their effects on other organisms (e.g., antimicrobial effects), mainly in the area of medicine. Concerning the long evolutionary history of algae and their distribution in highly diverse ecological settings from freshwaters to terrestrial ecosystems, one can expect a myriad of different metabolites from algae. This seems to be the case with novel secondary metabolites that are continuously reported from various algal species. Based on the discovery of active metabolites in medicine, where most of the work is done, similar results against plant pathogens can be expected. A limited number of biopesticidal extracts or compounds from algae have usually been reported from seaweeds or cyanobacteria. Therefore, macro- and microalgae represent a large untapped resource for the discovery of novel biopesticide compounds.

Author Contributions: Conceptualization, G.T. (George Tsiamis) and M.Y.; writing—original draft preparation, G.T. (George Tsiamis), E.A. and M.Y.; writing-review and editing, E.A., A.A.S., W.E., F.A., S.L., S.B., M.E., S.N., G.T. (Gökçe Taner), H.M.-S., M.Y. and G.T. (George Tsiamis); All authors have read and agreed to the published version of the manuscript.

Funding: The project entitled "Development of Bio-Pesticides and -Herbicides for Sustainable Agricultural Crop Production", Acronym "BIOPESTICIDES" is funded by the Federal Ministry of Education and Research, Germany (No. 01DH21010A), General Direction of Scientific Research and Technological Development (DGRSDT-Algeria), the General Secretariat for Research and Innovation of the Ministry of Development and Investments of Greece (ГГРRM-0357185 and ГГРRM-0357186), the Scientific and Technological Research Council of Turkey (TÜBİTAK) (121N251 and 121N259) under the PRIMA Programme. PRIMA is an Art.185 initiative supported and co-funded under Horizon 2020, the European Union's Programme for Research, and Innovation. This project is also partially funded by PerNaturam GmbH. 


\section{Institutional Review Board Statement: Not applicable.}

Informed Consent Statement: Not applicable.

Acknowledgments: We thank Sandra Radziej for expert help in the preparation of the figures.

Conflicts of Interest: The authors declare no conflict of interest.

\section{References}

1. Gärtner, G.; Stoyneva-Gärtner, M.; Uzunov, B. Algal Toxic Compounds and Their Aeroterrestrial, Airborne and Other Extremophilic Producers with Attention to Soil and Plant Contamination: A Review. Toxins 2021, 13, 322. [CrossRef] [PubMed]

2. $\quad$ Specht, E.A.; Karunanithi, P.S.; Gimpel, J.A.; Ansari, W.S.; Mayfield, S.P. Host Organisms: Algae. In Industrial Biotechnology; John Wiley \& Sons, Ltd.: Hoboken, NJ, USA, 2017; pp. 605-641. ISBN 978-3-527-80779-6.

3. Yan, N.; Fan, C.; Chen, Y.; Hu, Z. The Potential for Microalgae as Bioreactors to Produce Pharmaceuticals. Int. J. Mol. Sci. 2016, 17, 962. [CrossRef] [PubMed]

4. Rosales-Mendoza, S.; García-Silva, I.; González-Ortega, O.; Sandoval-Vargas, J.M.; Malla, A.; Vimolmangkang, S. The Potential of Algal Biotechnology to Produce Antiviral Compounds and Biopharmaceuticals. Molecules 2020, 25, 4049. [CrossRef] [PubMed]

5. Ibañez, E.; Cifuentes, A. Benefits of Using Algae as Natural Sources of Functional Ingredients. J. Sci. Food Agric. 2013, 93, 703-709. [CrossRef]

6. Singh, R.; Parihar, P.; Singh, M.; Bajguz, A.; Kumar, J.; Singh, S.; Singh, V.P.; Prasad, S.M. Uncovering Potential Applications of Cyanobacteria and Algal Metabolites in Biology, Agriculture and Medicine: Current Status and Future Prospects. Front. Microbiol. 2017, 8, 515. [CrossRef]

7. De Jesus Raposo, M.F.; De Morais, A.M.B.; De Morais, R.M.S.C. Marine Polysaccharides from Algae with Potential Biomedical Applications. Mar. Drugs 2015, 13, 2967-3028. [CrossRef]

8. Cardozo, K.H.M.; Guaratini, T.; Barros, M.P.; Falcão, V.R.; Tonon, A.P.; Lopes, N.P.; Campos, S.; Torres, M.A.; Souza, A.O.; Colepicolo, P.; et al. Metabolites from Algae with Economical Impact. Comp. Biochem. Physiol. Part C Toxicol. Pharmacol. 2007, 146, 60-78. [CrossRef]

9. Hamed, I.; Özogul, F.; Özogul, Y.; Regenstein, J.M. Marine Bioactive Compounds and Their Health Benefits: A Review. Compr. Rev. Food Sci. Food Saf. 2015, 14, 446-465. [CrossRef]

10. Mayer, A.M.S.; Rodríguez, A.D.; Berlinck, R.G.S.; Fusetani, N. Marine Pharmacology in 2007-8: Marine Compounds with Antibacterial, Anticoagulant, Antifungal, Anti-Inflammatory, Antimalarial, Antiprotozoal, Antituberculosis, and Antiviral Activities; Affecting the Immune and Nervous System, and Other Miscellaneous Mechanisms of Action. Comp. Biochem. Physiol. Part C Toxicol. Pharmacol. 2011, 153, 191-222. [CrossRef]

11. Wang, L.; Wang, X.; Wu, H.; Liu, R. Overview on Biological Activities and Molecular Characteristics of Sulfated Polysaccharides from Marine Green Algae in Recent Years. Mar. Drugs 2014, 12, 4984-5020. [CrossRef]

12. Fletcher, S.P.; Muto, M.; Mayfield, S.P. Optimization of Recombinant Protein Expression in the Chloroplasts of Green Algae. In Transgenic Microalgae as Green Cell Factories; León, R., Galván, A., Fernández, E., Eds.; Advances in Experimental Medicine and Biology; Springer: New York, NY, USA, 2007; pp. 90-98. ISBN 978-0-387-75532-8.

13. Cheung, R.C.F.; Wong, J.H.; Pan, W.L.; Chan, Y.S.; Yin, C.M.; Dan, X.L.; Wang, H.X.; Fang, E.F.; Lam, S.K.; Ngai, P.H.K.; et al Antifungal and Antiviral Products of Marine Organisms. Appl. Microbiol. Biotechnol. 2014, 98, 3475-3494. [CrossRef]

14. Hamed, S.M.; Abd El-Rhman, A.A.; Abdel-Raouf, N.; Ibraheem, I.B.M. Role of Marine Macroalgae in Plant Protection \& Improvement for Sustainable Agriculture Technology. Beni-Suef Univ. J. Basic Appl. Sci. 2018, 7, 104-110. [CrossRef]

15. Kulik, M.M. The Potential for Using Cyanobacteria (Blue-Green Algae) and Algae in the Biological Control of Plant Pathogenic Bacteria and Fungi. Eur. J. Plant Pathol. 1995, 101, 585-599. [CrossRef]

16. Kumar, K.A.; Rengasamy, R. Antibacterial Activities of Seaweed Extracts/Fractions Obtained through a TLC Profile against the Phytopathogenic Bacterium Xanthomonas Oryzae Pv. Oryzae. Bot. Mar. 2000, 43, 417-421. [CrossRef]

17. Jiménez, E.; Dorta, F.; Medina, C.; Ramírez, A.; Ramírez, I.; Peña-Cortés, H. Anti-Phytopathogenic Activities of Macro-Algae Extracts. Mar. Drugs 2011, 9, 739-756. [CrossRef]

18. Esserti, S.; Smaili, A.; Rifai, L.A.; Koussa, T.; Makroum, K.; Belfaiza, M.; Kabil, E.M.; Faize, L.; Burgos, L.; Alburquerque, N.; et al. Protective Effect of Three Brown Seaweed Extracts against Fungal and Bacterial Diseases of Tomato. J. Appl. Phycol. 2017, 29, 1081-1093. [CrossRef]

19. Caccamese, S.; Azzolina, R.; Furnari, G.; Cormaci, M.; Grasso, S. Antimicrobial and Antiviral Activities of Some Marine Algae from Eastern Sicily. Bot. Mar. 1981, 24, 365-368. [CrossRef]

20. Biondi, N.; Piccardi, R.; Margheri, M.C.; Rodolfi, L.; Smith, G.D.; Tredici, M.R. Evaluation of Nostoc Strain ATCC 53789 as a Potential Source of Natural Pesticides. Appl. Environ. Microbiol. 2004, 70, 3313-3320. [CrossRef]

21. Sano, Y. Antiviral Activity of Alginate against Infection by Tobacco Mosaic Virus. Carbohydr. Polym. 1999, 38, 183-186. [CrossRef]

22. Nagorskaia, V.P.; Reunov, A.V.; Lapshina, L.A.; Ermak, I.M.; Barabanova, A.O. Inhibitory effect of kappa/beta-carrageenan from red alga Tichocarpus crinitus on the development of a potato virus X infection in leaves of Datura stramonium L. Izv. Akad. Nauk. Ser. Biol. 2010, 6, 756-761. 
23. Pardee, K.I.; Ellis, P.; Bouthillier, M.; Towers, G.H.; French, C.J. Plant Virus Inhibitors from Marine Algae. Can. J. Bot. 2004, 82, 304-309. [CrossRef]

24. Sultana, V.; Baloch, G.N.; Ara, J.; Ehteshamul-Haque, S.; Tariq, R.M.; Athar, M. Seaweeds as an Alternative to Chemical Pesticides for the Management of Root Diseases of Sunflower and Tomato. J. Appl. Bot. Food Qual. 2012, 84, 162.

25. Ali, M.Y.S.; Ravikumar, S.; Beula, J.M. Mosquito Larvicidal Activity of Seaweeds Extracts against Anopheles Stephensi, Aedes aegypti and Culex Quinquefasciatus. Asian Pac. J. Trop. Dis. 2013, 3, 196-201. [CrossRef]

26. Hankins, S.D.; Hockey, H.P. The Effect of a Liquid Seaweed Extract from Ascophyllum nodosum (Fucales, Phaeophyta) on the Two-Spotted Red Spider Mite Tetranychus Urticae. Hydrobiologia 1990, 204, 555-559. [CrossRef]

27. Rashwan, R.S.; Hammad, D.M. Toxic Effect of Spirulina Platensis and Sargassum Vulgar as Natural Pesticides on Survival and Biological Characteristics of Cotton Leaf Worm Spodoptera littoralis. Sci. Afr. 2020, 8, e00323. [CrossRef]

28. López-González, D.; Ledo, D.; Cabeiras-Freijanes, L.; Verdeguer, M.; Reigosa, M.J.; Sánchez-Moreiras, A.M. Phytotoxic Activity of the Natural Compound Norharmane on Crops, Weeds and Model Plants. Plants 2020, 9, 1328. [CrossRef]

29. Gleason, F.K.; Case, D.E. Activity of the Natural Algicide, Cyanobacterin, on Angiosperms. Plant Physiol. 1986, 80, 834-837. [CrossRef]

30. Zhao, L.; Feng, C.; Wu, K.; Chen, W.; Chen, Y.; Hao, X.; Wu, Y. Advances and Prospects in Biogenic Substances against Plant Virus: A Review. Pestic. Biochem. Physiol. 2017, 135, 15-26. [CrossRef]

31. Gerasimenko, N.I.; Martyyas, E.A.; Logvinov, S.V.; Busarova, N.G. Biological Activity of Lipids and Photosynthetic Pigments of Sargassum pallidum C. Agardh. Appl. Biochem. Microbiol. 2014, 50, 73-81. [CrossRef]

32. Kumar, C.S.; Sarada, D.V.L.; Rengasamy, R. Seaweed Extracts Control the Leaf Spot Disease of the Medicinal Plant Gymnema Sylvestre. Indian J. Sci. Technol. 2008, 1, 1-5. [CrossRef]

33. Arun Kumar, K.; Selvapalam, N.; Rengasamy, R. The Antibacterial Compound Sulphoglycerolipid 1-0 Palmitoyl-3-0(6'-Sulpho- $\alpha-$ Quinovopyranosyl)-Glycerol from Sargassum wightii Greville (Phaeophyceae). Bot. Mar. 2005, 48, 441-445. [CrossRef]

34. Paulert, R.J.; Smania Stadnik, M.J.; Pizzolatti, M.G. Antimicrobial Properties of Extracts from the Green Seaweed Ulva fasciata Delile against Pathogenic Bacteria and Fungi. Algol. Stud. 2007, 123, 123-130. [CrossRef]

35. Ibraheem, B.M.I.; Hamed, S.M.; Abd Elrhman, A.A.; Farag, M.F.; Abdel-Raouf, N. Antimicrobial Activities of Some Brown Macroalgae against Some Soil Borne Plant Pathogens and in Vivo Management of Solanum melongena Root Diseases. Aust. J. Basic Appl. Sci. 2017, 11, 157-168.

36. Smyrniotopoulos, V.; Vagias, C.; Rahman, M.M.; Gibbons, S.; Roussis, V. Structure and Antibacterial Activity of Brominated Diterpenes from the Red Alga Sphaerococcus coronopifolius. Chem. Biodivers. 2010, 7, 186-195. [CrossRef]

37. Smyrniotopoulos, V.; Vagias, C.; Rahman, M.M.; Gibbons, S.; Roussis, V. Ioniols I and II, Tetracyclic Diterpenes with Antibacterial Activity, from Sphaerococcus coronopifolius. Chem. Biodivers. 2010, 7, 666-676. [CrossRef]

38. Kuniyoshi, M.; Yamada, K.; Higa, T. A Biologically Active Diphenyl Ether from the Green AlgaCladophora Fascicularis. Experientia 1985, 41, 523-524. [CrossRef]

39. Al-Saif, S.S.A.; Abdel-Raouf, N.; El-Wazanani, H.A.; Aref, I.A. Antibacterial Substances from Marine Algae Isolated from Jeddah Coast of Red Sea, Saudi Arabia. Saudi J. Biol. Sci. 2014, 21, 57-64. [CrossRef]

40. Abdel-Raouf, N.; Al-Enazi, N.M.; Al-Homaidan, A.A.; Ibraheem, I.B.M.; Al-Othman, M.R.; Hatamleh, A.A. Antibacterial $\beta$-Amyrin Isolated from Laurencia Microcladia. Arab. J. Chem. 2015, 8, 32-37. [CrossRef]

41. Mohy El-Din, S.M.; El-Ahwany, A.M.D. Bioactivity and Phytochemical Constituents of Marine Red Seaweeds (Jania rubens, Corallina mediterranea and Pterocladia capillacea). J. Taibah Univ. Sci. 2016, 10, 471-484. [CrossRef]

42. Asthana, R.K.; Tripathi, M.K.; Srivastava, A.; Singh, A.P.; Singh, S.P.; Nath, G.; Srivastava, R.; Srivastava, B.S. Isolation and Identification of a New Antibacterial Entity from the Antarctic cyanobacterium Nostoc CCC 537 . J. Appl. Phycol. 2008, 21, 81. [CrossRef]

43. Borbón, H.; Herrera, J.M.; Calvo, M.; Sierra, H.T.L.; Soto, R.; Vega, I. Antimicrobial Activity of Most Abundant Marine Macroalgae of the Caribbean Coast of Costa Rica. J. Asian Sci. Res. 2012, 2, 292.

44. Pesando, D.; Caram, B. Screening of Marine Algae from the French Mediterranean Coast for Antibacterial and Antifungal Activity. Bot. Mar. 1984, 27, 381-386. [CrossRef]

45. Rao, P.S.; Parekh, K.S. Antibacterial Activity of Indian Seaweed Extracts. Bot. Mar. 1981, 24, 577-582. [CrossRef]

46. Salvador, N.; Garreta, A.G.; Lavelli, L.; Ribera, M.A. Antimicrobial Activity of Iberian Macroalgae. Sci. Mar. 2007, 71, 101-114. [CrossRef]

47. Ioannou, E.; Quesada, A.; Rahman, M.M.; Gibbons, S.; Vagias, C.; Roussis, V. Structures and Antibacterial Activities of Minor Dolabellanes from the Brown Alga Dilophus spiralis. Eur. J. Org. Chem. 2012, 2012, 5177-5186. [CrossRef]

48. Abdel-Raouf, N.; Ibraheem, I.B. Antibiotic Activity of Two Anabaena Species against Four Fish Pathogenic Aeromonas Species. Afr. J. Biotechnol. 2008, 7, 2644-2648.

49. Ramkissoon, A.; Ramsubhag, A.; Jayaraman, J. Phytoelicitor Activity of Three Caribbean Seaweed Species on Suppression of Pathogenic Infections in Tomato Plants. J. Appl. Phycol. 2017, 29, 3235-3244. [CrossRef]

50. Vera, J.; Castro, J.; Gonzalez, A.; Moenne, A. Seaweed Polysaccharides and Derived Oligosaccharides Stimulate Defense Responses and Protection Against Pathogens in Plants. Mar. Drugs 2011, 9, 2514-2525. [CrossRef] 
51. Aziz, E.; Batool, R.; Khan, M.U.; Rauf, A.; Akhtar, W.; Heydari, M.; Rehman, S.; Shahzad, T.; Malik, A.; Mosavat, S.H.; et al. An Overview on Red Algae Bioactive Compounds and Their Pharmaceutical Applications. J. Complementary Integr. Med. 2020, 17, 20190203. [CrossRef]

52. Nagorskaia, V.P.; Reunov, A.V.; Lapshina, L.A.; Ermak, I.M.; Barabanova, A.O. Influence of kappa/beta-carrageenan from red alga Tichocarpus crinitus on development of local infection induced by tobacco mosaic virus in Xanthi-nc tobacco leaves. Izv. Akad. Nauk. Ser. Biol. 2008, 3, 360-364.

53. Wang, S.; Zhong, F.-D.; Zhang, Y.-J.; Wu, Z.-J.; Lin, Q.-Y.; Xie, L.-H. Molecular Characterization of a New Lectin from the Marine Alga Ulva Pertusa. Acta Biochim. Biophys. Sin. 2004, 36, 111-117. [CrossRef] [PubMed]

54. Liu, Z.Y.; Xie, L.Y.; Wu, Z.J.; Lin, Q.Y.; Xie, L.H. Purification and Characterization of Anti-TMV Protein from a Marine Algae Ulva Pertusa. Acta Phytopathol. Sin. 2005, 35, 256-261.

55. Aguilar-Briseño, J.A.; Cruz-Suarez, L.E.; Sassi, J.-F.; Ricque-Marie, D.; Zapata-Benavides, P.; Mendoza-Gamboa, E.; RodríguezPadilla, C.; Trejo-Avila, L.M. Sulphated Polysaccharides from Ulva clathrata and Cladosiphon okamuranus Seaweeds Both Inhibit Viral Attachment/Entry and Cell-Cell Fusion, in NDV Infection. Mar. Drugs 2015, 13, 697-712. [CrossRef] [PubMed]

56. Moga, M.A.; Dima, L.; Balan, A.; Blidaru, A.; Dimienescu, O.G.; Podasca, C.; Toma, S. Are Bioactive Molecules from Seaweeds a Novel and Challenging Option for the Prevention of HPV Infection and Cervical Cancer Therapy?-A Review. Int. J. Mol. Sci. 2021, 22, 629. [CrossRef] [PubMed]

57. Artan, M.; Li, Y.; Karadeniz, F.; Lee, S.-H.; Kim, M.-M.; Kim, S.-K. Anti-HIV-1 Activity of Phloroglucinol Derivative, 6,6'-Bieckol, from Ecklonia Cava. Bioorg. Med. Chem. 2008, 16, 7921-7926. [CrossRef] [PubMed]

58. Wu, L.; Wang, W.; Zhang, X.; Zhao, X.; Yu, G. Anti-HBV Activity and Mechanism of Marine-Derived Polyguluronate Sulfate (PGS) In Vitro. Carbohydr. Polym. 2016, 143, 139-148. [CrossRef]

59. Harden, E.A.; Falshaw, R.; Carnachan, S.M.; Kern, E.R.; Prichard, M.N. Virucidal Activity of Polysaccharide Extracts from Four Algal Species against Herpes Simplex Virus. Antivir. Res. 2009, 83, 282-289. [CrossRef]

60. Talarico, L.B.; Duarte, M.E.R.; Zibetti, R.G.M.; Noseda, M.D.; Damonte, E.B. An Algal-Derived DL-Galactan Hybrid Is an Efficient Preventing Agent for In Vitro Dengue Virus Infection. Planta Med. 2007, 73, 1464-1468. [CrossRef]

61. Carbone, D.A.; Pellone, P.; Lubritto, C.; Ciniglia, C. Evaluation of Microalgae Antiviral Activity and Their Bioactive Compounds. Antibiotics 2021, 10, 746. [CrossRef]

62. Mitchell, C.A.; Ramessar, K.; O'Keefe, B.R. Antiviral Lectins: Selective Inhibitors of Viral Entry. Antivir. Res. 2017, 142, 37-54 [CrossRef]

63. Arad, S.; Adda, M.; Cohen, E. The Potential of Production of Sulfated Polysaccharides from Porphyridium. Plant Soil 1985, 89, 117-127. [CrossRef]

64. Abu-Ghannam, N.; Rajauria, G. 8-Antimicrobial Activity of Compounds Isolated from Algae. In Functional Ingredients from Algae for Foods and Nutraceuticals; Domínguez, H., Ed.; Woodhead Publishing Series in Food Science, Technology and Nutrition; Woodhead Publishing: Sawston, Cambridge, UK, 2013; pp. 287-306. ISBN 978-0-85709-512-1.

65. Baloch, G.N.; Tariq, S.; Ehteshamul-Haque, S.; Athar, M.; Sultana, V.; Ara, J. Management of Root Diseases of Eggplant and Watermelon with the Application of Asafoetida and Seaweeds. J. Appl. Bot. Food Qual. 2013, 86, 138-142.

66. Begum, A.J.M.; Selvaraju, P.; Vijayakumar, A. Evaluation of Antifungal Activity of Seaweed Extract (Turbinaria conoides) against Fusarium oxysporum. J. Appl. Nat. Sci. 2016, 8, 60-62. [CrossRef]

67. Cluzet, S.; Torregrosa, C.; Jacquet, C.; Lafitte, C.; Fournier, J.; Mercier, L.; Salamagne, S.; Briand, X.; Esquerré-Tugayé, M.-T.; Dumas, B. Gene Expression Profiling and Protection of Medicago truncatula against a Fungal Infection in Response to an Elicitor from Green Algae Ulva Spp. Plant Cell Environ. 2004, 27, 917-928. [CrossRef]

68. De Corato, U.; Salimbeni, R.; De Pretis, A.; Avella, N.; Patruno, G. Antifungal Activity of Crude Extracts from Brown and Red Seaweeds by a Supercritical Carbon Dioxide Technique against Fruit Postharvest Fungal Diseases. Postharvest Biol. Technol. 2017, 131, 16-30. [CrossRef]

69. Galal, H.R.M.; Salem, W.M.; Nasr El-Deen, F. Biological Control of Some Pathogenic Fungi Using Marine Algae. Res. J. Microbiol. 2011, 6, 645-657. [CrossRef]

70. Khallil, A.M.; Daghman, I.M. Antifungal Potential in Crude Extracts of Five Selected Brown Seaweeds Collected from the Western Libya Coast. J. Micro Creat. 2015, 1, 103.

71. Kim, J.; Kim, J.-D. Inhibitory Effect of Algal Extracts on Mycelial Growth of the Tomato-Wilt Pathogen, Fusarium oxysporum f. sp lycopersici. Mycobiology 2008, 36, 242-248. [CrossRef]

72. Mahakhant, A.; Padungwong, P.; Arunpairojana, V.; Atthasampunna, P. Control of the Plant Pathogenic Fungus Macrophomina phaseolina in Mung Bean by a Microalgal Extract. Phycol. Res. 1998, 46, 3-7. [CrossRef]

73. Prasanna, R.; Chaudhary, V.; Gupta, V.; Babu, S.; Kumar, A.; Singh, R.; Shivay, Y.S.; Nain, L. Cyanobacteria Mediated Plant Growth Promotion and Bioprotection against Fusarium Wilt in Tomato. Eur. J. Plant Pathol. 2013, 136, 337-353. [CrossRef]

74. Roberti, R.; Righini, H.; Reyes, C.P. Activity of Seaweed and Cyanobacteria Water Extracts against Podosphaera xanthii on Zucchini. Ital. J. Mycol. 2016, 45, 66-77. [CrossRef]

75. Soliman, A.S.; Ahmed, A.Y.; Abdel-Ghafour, S.E.; El-Sheekh, M.M.; Sobhy, H.M. Antifungal Bio-Efficacy of the Red Algae Gracilaria confervoides Extracts against Three Pathogenic Fungi of Cucumber Plant. Middle East J. Appl. Sci. 2018, 8, 727-735.

76. Sultana, V.; Ehteshamul-Haque, S.; Ara, J.; Athar, M. Comparative Efficacy of Brown, Green and Red Seaweeds in the Control of Root Infecting Fungi and Okra. Int. J. Environ. Sci. Technol. 2005, 2, 129-132. [CrossRef] 
77. Ben Salah, I.; Aghrouss, S.; Douira, A.; Aissam, S.; El Alaoui-Talibi, Z.; Filali-Maltouf, A.; El Modafar, C. Seaweed Polysaccharides as Bio-Elicitors of Natural Defenses in Olive Trees against Verticillium Wilt of Olive. J. Plant Interact. 2018, 13, 248-255. [CrossRef]

78. de Borba, M.C.; de Freitas, M.B.; Stadnik, M.J. Ulvan Enhances Seedling Emergence and Reduces Fusarium Wilt Severity in Common Bean (Phaseolus vulgaris L.). Crop Prot. 2019, 118, 66-71. [CrossRef]

79. de Freitas, M.B.; Stadnik, M.J. Race-Specific and Ulvan-Induced Defense Responses in Bean (Phaseolus vulgaris) against Colletotrichum lindemuthianum. Physiol. Mol. Plant Pathol. 2012, 78, 8-13. [CrossRef]

80. Jaulneau, V.; Lafitte, C.; Corio-Costet, M.-F.; Stadnik, M.J.; Salamagne, S.; Briand, X.; Esquerré-Tugayé, M.-T.; Dumas, B. An Ulva armoricana Extract Protects Plants against Three Powdery Mildew Pathogens. Eur. J. Plant Pathol. 2011, 131, 393. [CrossRef]

81. Kobayashi, A.; Tai, A.; Kanzaki, H.; Kawazu, K. Elicitor-Active Oligosaccharides from Algal Laminaran Stimulate the Production of Antifungal Compounds in Alfalfa. Z. Für Nat. C 1993, 48, 575-579. [CrossRef]

82. Paulert, R.; Ebbinghaus, D.; Urlass, C.; Moerschbacher, B.M. Priming of the Oxidative Burst in Rice and Wheat Cell Cultures by Ulvan, a Polysaccharide from Green Macroalgae, and Enhanced Resistance against Powdery Mildew in Wheat and Barley Plants. Plant Pathol. 2010, 59, 634-642. [CrossRef]

83. Paulert, R.; Talamini, V.; Cassolato, J.E.F.; Duarte, M.E.R.; Noseda, M.D.; Smania, A.; Stadnik, M.J. Effects of Sulfated Polysaccharide and Alcoholic Extracts from Green Seaweed Ulva fasciata on Anthracnose Severity and Growth of Common Bean (Phaseolus vulgaris L.). J. Plant Dis. Prot. 2009, 116, 263-270. [CrossRef]

84. Stadnik, M.J.; de Freitas, M.B. Algal Polysaccharides as Source of Plant Resistance Inducers. Trop. Plant Pathol. 2014, 39, 111-118. [CrossRef]

85. Aziz, A.; Poinssot, B.; Daire, X.; Adrian, M.; Bézier, A.; Lambert, B.; Joubert, J.-M.; Pugin, A. Laminarin Elicits Defense Responses in Grapevine and Induces Protection Against Botrytis cinerea and Plasmopara viticola. Mol. Plant-Microbe Interact. 2003, 16, 1118-1128. [CrossRef] [PubMed]

86. Righini, H.; Baraldi, E.; García Fernández, Y.; Martel Quintana, A.; Roberti, R. Different Antifungal Activity of Anabaena sp., Ecklonia sp., and Jania sp. against Botrytis cinerea. Mar. Drugs 2019, 17, 299. [CrossRef] [PubMed]

87. Hernández-Herrera, R.M.; Virgen-Calleros, G.; Ruiz-López, M.; Zañudo-Hernández, J.; Délano-Frier, J.P.; Sánchez-Hernández, C. Extracts from Green and Brown Seaweeds Protect Tomato (Solanum lycopersicum) against the Necrotrophic Fungus Alternaria solani. J. Appl. Phycol. 2014, 26, 1607-1614. [CrossRef]

88. Araujo, L.; Stadnik, M.J. Cultivar-Specific and Ulvan-Induced Resistance of Apple Plants to Glomerella Leaf Spot Are Associated with Enhanced Activity of Peroxidases. Acta Sci. Agron. 2013, 35, 287-293. [CrossRef]

89. El-Sheekh, M.M.; Ahmed, A.Y.; Soliman, A.S.; Abdel-Ghafour, S.E.; Sobhy, H.M. Biological Control of Soil Borne Cucumber Diseases Using Green Marine Macroalgae. Egypt. J. Biol. Pest Control 2021, 31, 72. [CrossRef]

90. Ammar, N.; Jabnoun-Khiareddine, H.; Mejdoub-Trabelsi, B.; Nefzi, A.; Mahjoub, M.A.; Daami-Remadi, M. Pythium Leak Control in Potato Using Aqueous and Organic Extracts from the Brown Alga Sargassum vulgare (C. Agardh, 1820). Postharvest Biol. Technol. 2017, 130, 81-93. [CrossRef]

91. Raj, T.S.; Graff, K.H.; Suji, H.A. Bio Chemical Characterization of a Brown Seaweed Algae and Its Efficacy on Control of Rice Sheath Blight Caused by Rhizoctonia solani Kuhn. Int. J. Trop. Agric. 2016, 34, 429-439.

92. Veronico, P.; Melillo, M.T. Marine Organisms for the Sustainable Management of Plant Parasitic Nematodes. Plants 2021, 10, 369 [CrossRef]

93. Awad, N.E. Bioactive Brominated Diterpenes from the Marine Red Alga Jania rubens (L.) Lamx. Phytother. Res. 2004, 18, 275-279. [CrossRef]

94. Ara, J.; Ehteshamul-Haque, S.; Sultana, V.; Ghaffar, A.; Qasim, R. Use of Sargassum Species for the Control of Meloidogyne Javanica in Okra. Nematol. Mediterr. 1997, 25, 125-128.

95. Rizvi, M.A.; Shameel, M. In Vitro Nematicidal Activities of Seaweed Extracts from Karachi Coast. Pak. J. Bot. 2006, $38,1245$.

96. Featonby-Smith, B.C.; Van Staden, J. The Effect of Seaweed Concentrate on the Growth of Tomato Plants in Nematode-Infested Soil. Sci. Hortic. 1983, 20, 137-146. [CrossRef]

97. Ngala, B.M.; Valdes, Y.; dos Santos, G.; Perry, R.N.; Wesemael, W.M.L. Seaweed-Based Products from Ecklonia maxima and Ascophyllum nodosum as Control Agents for the Root-Knot Nematodes Meloidogyne chitwoodi and Meloidogyne hapla on Tomato Plants. J. Appl. Phycol. 2016, 28, 2073-2082. [CrossRef]

98. Morgan, K.T.; Tarjan, A.C. Management of Sting Nematode on Centipede Grass with Kelp Extracts. Proc. Fla. State Hort. Soc. 1980, 93, 97-99.

99. Radwan, M.A.; Farrag, S.A.A.; Abu-Elamayem, M.M.; Ahmed, N.S. Biological Control of the Root-Knot Nematode, Meloidogyne Incognita on Tomato Using Bioproducts of Microbial Origin. Appl. Soil Ecol. 2012, 56, 58-62. [CrossRef]

100. Radwan, M.A.; Abu-Elamayem, M.M.; Farrag, S.A.A.; Ahmed, N.S. Integrated Management of Meloidogyne Incognita Infecting Tomato Using Bio-Agents Mixed with Either Oxamyl or Organic Amendments. Nematol. Mediterr. 2011, 39, $151-156$.

101. Tarjan, A.C. Kelp Derivatives for Nematode-Infected Citrus Trees. J. Nematol. 1977, 9, 287.

102. Isman, M.B. Leads and Prospects for the Development of New Botanical Insecticides. Rev. Pestic. Toxicol. 1995, 3, 1-20.

103. Schrader, K.K.; Nagle, D.G.; Wedge, D.E. Algal and Cyanobacterial Metabolites as Agents for Pest Management. In Advances in Microbial Toxin Research and Its Biotechnological Exploitation; Upadhyay, R.K., Ed.; Springer: Boston, MA, USA, $2002 ;$ pp. 171-195. ISBN 978-1-4757-4439-2. 
104. Argandoña, V.; Del Pozo, T.; San-Martín, A.; Rovirosa, J. Insecticidal Activity of Plocamium cartilagineum Monoterpenes. Boletín de la Sociedad Chilena de Química 2000, 45, 371-376. [CrossRef]

105. Asha, A.; Rathi, J.M.; Raja, D.P.; Sahayaraj, K. Biocidal Activity of Two Marine Green Algal Extracts against Third Instar Nymph of Dysdercus cingulatus (Fab.)(Hemiptera: Pyrrhocoridae). J. Biopest. 2012, 5, 129-134.

106. Asharaja, A.; Sahayaraj, K. Screening of Insecticidal Activity of Brown Macroalgal Extracts against Dysdercus cingulatus (Fab.)(Hemiptera: Pyrrhocoridae). J. Biopest. 2013, 6, 193-203.

107. Bantoto, V.; Dy, D. The Larvicidal Activity of Brown Algae Padina Minor (Yamada 1925) and Dicyota linearis (Greville 1830) against the Dengue Vector, Aedes aegypti (Linn 1762)(Diptera: Culicidae). J. Vector Borne Dis. 2013, 50, 68. [PubMed]

108. Cetin, H.; Gokoglu, M.; Oz, E. Larvicidal Activity of the Extract of Seaweed, Caulerpa scalpelliformis, Against Culex pipiens. J. Am. Mosq. Control. Assoc. 2010, 26, 433-435. [CrossRef]

109. González-Castro, A.L.; Muñoz-Ochoa, M.; Hernández-Carmona, G.; López-Vivas, J.M. Evaluation of Seaweed Extracts for the Control of the Asian Citrus Psyllid Diaphorina citri. J. Appl. Phycol. 2019, 31, 3815-3821. [CrossRef]

110. Kiviranta, J.; Abdel-Hameed, A.; Sivonen, K.; Niemelä, S.I.; Carlberg, G. Toxicity of Cyanobacteria to Mosquito Larvae-Screening of Active Compounds. Environ. Toxicol. Water Qual. 1993, 8, 63-71. [CrossRef]

111. Rima, M.; Chbani, A.; Roques, C.; El Garah, F. Comparative Study of the Insecticidal Activity of a High Green Plant (Spinacia oleracea) and a Chlorophytae algae (Ulva lactuca) Extracts against Drosophila melanogaster Fruit Fly. Ann. Pharm. Françaises 2021, 79, 36-43. [CrossRef]

112. Ruangsomboon, S.; Pumnuan, J. Acaricidal Activities of Algal Extracts against the House Dust Mite, Dermatophagoides Pteronyssinus (Trouessart). J. Acarol. Soc. Jpn. 2016, 25, S169-S178. [CrossRef]

113. Saber, A.A.; Hamed, S.M.; Abdel-Rahim, E.F.M.; Cantonati, M. Insecticidal Prospects of Algal and Cyanobacterial Extracts against the Cotton Leafworm Spodoptera littoralis. Vie Et Milieu 2018, 68, 199-212.

114. Sahayaraj, K.; Jeeva, Y.M. Nymphicidal and Ovipositional Efficacy of Seaweed Sargassum tenerrimum (J. Agardh) against Dysdercus cingulatus (Fab.) (Pyrrhocoridae). Chil. J. Agric. Res. 2012, 72, 152-156. [CrossRef]

115. Sahayaraj, K.; Kalidas, S. Evaluation of Nymphicidal and Ovicidal Effect of a Seaweed, Padina pavonica (Linn.)(Phaeophyceae) on Cotton Pest, Dysdercus cingulatus (Fab.). Indian J. Geo-Mar. Sci. 2011, 40, 125-129.

116. Yu, K.-X.; Jantan, I.; Ahmad, R.; Wong, C.-L. The Major Bioactive Components of Seaweeds and Their Mosquitocidal Potential. Parasitol. Res. 2014, 113, 3121-3141. [CrossRef] [PubMed]

117. Abbassy, M.A.; Marzouk, M.A.; Rabea, E.I.; Abd-Elnabi, A.D. Insecticidal and Fungicidal Activity of Ulva lactuca Linnaeus (Chlorophyta) Extracts and Their Fractions. Annu. Res. Rev. Biol. 2014, 4, 2252-2262. [CrossRef]

118. Kombiah, P.; Sahayaraj, K. Repellent Activity of Caulerpa scalpelliformis Extracts and Its Formulations against Spodoptera litura and Dysdercus cingulatus (Fab.). J. Biopestic. 2012, 5, 145.

119. Pasdaran, A.; Hamedi, A.; Mamedov, N.A. Antibacterial and Insecticidal Activity of Volatile Compounds of Three Algae Species of Oman Sea. Int. J. Second. Metab. 2016, 3, 66-73. [CrossRef]

120. Cueto, G.M.; Zerba, E.; Picollo, M.I. Biological Effect of 1-Dodecanol in Teneral and Post-Teneral Rhodnius prolixus and Triatoma infestans (Hemiptera: Reduviidae). Mem. Inst. Oswaldo Cruz 2005, 100, 59-61. [CrossRef]

121. Dayan, F.E.; Cantrell, C.L.; Duke, S.O. Natural Products in Crop Protection. Bioorg. Med. Chem. 2009, 17, 4022-4034. [CrossRef]

122. Berry, J.P.; Gantar, M.; Perez, M.H.; Berry, G.; Noriega, F.G. Cyanobacterial Toxins as Allelochemicals with Potential Applications as Algaecides, Herbicides and Insecticides. Mar. Drugs 2008, 6, 117-146. [CrossRef]

123. Rastogi, R.P.; Sinha, R.P. Biotechnological and Industrial Significance of Cyanobacterial Secondary Metabolites. Biotechnol. Adv. 2009, 27, 521-539. [CrossRef]

124. Smith, G.D.; Thanh Doan, N. Cyanobacterial Metabolites with Bioactivity against Photosynthesis in Cyanobacteria, Algae and Higher Plants. J. Appl. Phycol. 1999, 11, 337-344. [CrossRef]

125. Żak, A.; Kosakowska, A. Cyanobacterial and Microalgal Bioactive Compounds-The Role of Secondary Metabolites in Allelopathic Interactions. Oceanol. Hydrobiol. Stud. 2016, 45, 131-143. [CrossRef]

126. Mohamed Allelopathic Activity of the Norharmane-Producing Cyanobacterium Synechocystis aquatilis against Cyanobacteria and Microalgae. Oceanol. Hydrobiol. Stud. 2013, 42, 1-7. [CrossRef]

127. Gromov, B.V.; Vepritskiy, A.A.; Titova, N.N.; Mamkayeva, K.A.; Alexandrova, O.V. Production of the Antibiotic Cyanobacterin LU-1 by Nostoc linckia CALU 892 (Cyanobacterium). J. Appl. Phycol. 1991, 3, 55-59. [CrossRef]

128. Ishibashi, F.; Park, S.; Kusano, T.; Kuwano, K. Synthesis and Algicidal Activity of (+)-Cyanobacterin and Its Stereoisomer. Biosci. Biotechnol. Biochem. 2005, 69, 391-396. [CrossRef]

129. Blom, J.F.; Brütsch, T.; Barbaras, D.; Bethuel, Y.; Locher, H.H.; Hubschwerlen, C.; Gademann, K. Potent Algicides Based on the Cyanobacterial Alkaloid Nostocarboline. Org. Lett. 2006, 8, 737-740. [CrossRef]

130. Hirata, K.; Yoshitomi, S.; Dwi, S.; Iwabe, O.; Mahakhant, A.; Polchai, J.; Miyamoto, K. Bioactivities of Nostocine a Produced by a Freshwater Cyanobacterium Nostoc spongiaeforme TISTR 8169. J. Biosci. Bioeng. 2003, 95, 512-517. [CrossRef]

131. Todorova, A.K.; Juettner, F.; Linden, A.; Pluess, T.; von Philipsborn, W. Nostocyclamide: A New Macrocyclic, Thiazole-Containing Allelochemical from Nostoc sp. 31 (Cyanobacteria). J. Org. Chem. 1995, 60, 7891-7895. [CrossRef]

132. Casanova, M.T.; Burch, M.D.; Brock, M.A.; Bond, P.M. Does Toxic Microcystis Aeruginosa Affect Aquatic Plant Establishment? Environ. Toxicol. 1999, 14, 97-109. [CrossRef] 
133. Jang, M.-H.; Ha, K.; Takamura, N. Reciprocal Allelopathic Responses between Toxic Cyanobacteria (Microcystis Aeruginosa) and Duckweed (Lemna japonica). Toxicon 2007, 49, 727-733. [CrossRef]

134. Brilisauer, K.; Rapp, J.; Rath, P.; Schöllhorn, A.; Bleul, L.; Weiß, E.; Stahl, M.; Grond, S.; Forchhammer, K. Cyanobacterial Antimetabolite 7-Deoxy-Sedoheptulose Blocks the Shikimate Pathway to Inhibit the Growth of Prototrophic Organisms. Nat. Commun. 2019, 10, 545. [CrossRef]

135. Craigie, J.S. Seaweed Extract Stimuli in Plant Science and Agriculture. J. Appl. Phycol. 2011, 23, 371-393. [CrossRef]

136. Crouch, I.J.; van Staden, J. Evidence for the Presence of Plant Growth Regulators in Commercial Seaweed Products. Plant Growth Regul. 1993, 13, 21-29. [CrossRef]

137. Khan, W.; Rayirath, U.P.; Subramanian, S.; Jithesh, M.N.; Rayorath, P.; Hodges, D.M.; Critchley, A.T.; Craigie, J.S.; Norrie, J.; Prithiviraj, B. Seaweed Extracts as Biostimulants of Plant Growth and Development. J. Plant Growth Regul. 2009, 28, 386-399. [CrossRef]

138. Lee, S.-M.; Ryu, C.-M. Algae as New Kids in the Beneficial Plant Microbiome. Front. Plant Sci. 2021, 12, 599742. [CrossRef]

139. Sharma, H.S.S.; Fleming, C.; Selby, C.; Rao, J.R.; Martin, T. Plant Biostimulants: A Review on the Processing of Macroalgae and Use of Extracts for Crop Management to Reduce Abiotic and Biotic Stresses. J. Appl. Phycol. 2014, 26, 465-490. [CrossRef]

140. Hines, S.; van der Zwan, T.; Shiell, K.; Shotton, K.; Prithiviraj, B. Alkaline Extract of the Seaweed Ascophyllum nodosum Stimulates Arbuscular Mycorrhizal Fungi and Their Endomycorrhization of Plant Roots. Sci. Rep. 2021, 11, 13491. [CrossRef]

141. Renaut, S.; Masse, J.; Norrie, J.P.; Blal, B.; Hijri, M. A Commercial Seaweed Extract Structured Microbial Communities Associated with Tomato and Pepper Roots and Significantly Increased Crop Yield. Microb. Biotechnol. 2019, 12, 1346-1358. [CrossRef]

142. Ali, O.; Ramsubhag, A.; Jayaraman, J. Biostimulatory Activities of Ascophyllum nodosum Extract in Tomato and Sweet Pepper Crops in a Tropical Environment. PLoS ONE 2019, 14, e0216710. [CrossRef]

143. Rayorath, P.; Khan, W.; Palanisamy, R.; MacKinnon, S.L.; Stefanova, R.; Hankins, S.D.; Critchley, A.T.; Prithiviraj, B. Extracts of the Brown Seaweed Ascophyllum nodosum Induce Gibberellic Acid (GA3)-Independent Amylase Activity in Barley. J. Plant Growth Regul. 2008, 27, 370-379. [CrossRef]

144. Stirk, W.A.; Arthur, G.D.; Lourens, A.F.; Novák, O.; Strnad, M.; van Staden, J. Changes in Cytokinin and Auxin Concentrations in Seaweed Concentrates When Stored at an Elevated Temperature. J. Appl. Phycol. 2004, 16, 31. [CrossRef]

145. Stirk, W.A.; Van Staden, J. Isolation and Identification of Cytokinins in a New Commercial Seaweed Product Made from Fucus serratus L. J. Appl. Phycol. 1997, 9, 327. [CrossRef]

146. Stirk, W.A.; Van Staden, J. Comparison of Cytokinin- and Auxin-like Activity in Some Commercially Used Seaweed Extracts. J. Appl. Phycol. 1996, 8, 503-508. [CrossRef]

147. Allen, V.G.; Pond, K.R.; Saker, K.E.; Fontenot, J.P.; Bagley, C.P.; Ivy, R.L.; Evans, R.R.; Schmidt, R.E.; Fike, J.H.; Zhang, X.; et al. Tasco: Influence of a Brown Seaweed on Antioxidants in Forages and Livestock-A Review. J. Anim. Sci. 2001, 79, E21-E31. [CrossRef]

148. Kim, M.-J.; Shim, C.-K.; Kim, Y.-K.; Ko, B.-G.; Park, J.-H.; Hwang, S.-G.; Kim, B.-H. Effect of Biostimulator Chlorella fusca on Improving Growth and Qualities of Chinese Chives and Spinach in Organic Farm. Plant Pathol. J. 2018, 34, 567-574. [CrossRef] [PubMed]

149. Shaaban, M.M. Green Microalgae Water Extract as Foliar Feeding to Wheat Plants. Pak. J. Biol. Sci. 2001, 4, 628-632. [CrossRef]

150. Shaaban, M.M. Nutritional Status and Growth of Maize Plants as Affected by Green Microalgae as Soil Additives. J. Biol. Sci. 2001, 1, 475-479. [CrossRef]

151. Barone, V.; Baglieri, A.; Stevanato, P.; Broccanello, C.; Bertoldo, G.; Bertaggia, M.; Cagnin, M.; Pizzeghello, D.; Moliterni, V.M.C.; Mandolino, G.; et al. Root Morphological and Molecular Responses Induced by Microalgae Extracts in Sugar Beet (Beta vulgaris L.). J. Appl. Phycol. 2018, 30, 1061-1071. [CrossRef]

152. Bumandalai, O.; Tserennadmid, R. Effect of Chlorella Vulgaris as a Biofertilizer on Germination of Tomato and Cucumber Seeds. Int. J. Aquat. Biol. 2019, 7, 95-99. [CrossRef]

153. Faheed, F.A.; Fattah, Z.A. Effect of Chlorella Vulgaris as Bio-Fertilizer on Growth Parameters and Metabolic Aspects of Lettuce Plant. J. Agric. Soc. Sci. 2008, 4, 165-169.

154. Coppens, J.; Grunert, O.; Van Den Hende, S.; Vanhoutte, I.; Boon, N.; Haesaert, G.; De Gelder, L. The Use of Microalgae as a High-Value Organic Slow-Release Fertilizer Results in Tomatoes with Increased Carotenoid and Sugar Levels. J. Appl. Phycol. 2016, 28, 2367-2377. [CrossRef]

155. Innok, S.; Chunleuchanon, S.; Boonkerd, N.; Teaumroong, N. Cyanobacterial Akinete Induction and Its Application as Biofertilizer for Rice Cultivation. J. Appl. Phycol. 2009, 21, 737. [CrossRef]

156. Singh, S.; Datta, P. Outdoor Evaluation of Herbicide Resistant Strains of Anabaena variabilis as Biofertilizer for Rice Plants. Plant Soil 2007, 296, 95-102. [CrossRef]

157. Kumar, M.; Prasanna, R.; Bidyarani, N.; Babu, S.; Mishra, B.K.; Kumar, A.; Adak, A.; Jauhari, S.; Yadav, K.; Singh, R.; et al. Evaluating the Plant Growth Promoting Ability of Thermotolerant Bacteria and Cyanobacteria and Their Interactions with Seed Spice Crops. Sci. Hortic. 2013, 164, 94-101. [CrossRef]

158. Karthikeyan, N.; Prasanna, R.; Sood, A.; Jaiswal, P.; Nayak, S.; Kaushik, B.D. Physiological Characterization and Electron Microscopic Investigation of Cyanobacteria Associated with Wheat Rhizosphere. Folia Microbiol. 2009, 54, 43-51. [CrossRef] [PubMed] 
159. Trejo Valencia, R.; Sánchez Acosta, L.; Fortis Hernández, M.; Preciado Rangel, P.; Gallegos Robles, M.Á.; Antonio Cruz, R.d.C.; Vázquez Vázquez, C. Effect of Seaweed Aqueous Extracts and Compost on Vegetative Growth, Yield, and Nutraceutical Quality of Cucumber (Cucumis sativus L.) Fruit. Agronomy 2018, 8, 264. [CrossRef]

160. Wuang, S.C.; Khin, M.C.; Chua, P.Q.D.; Luo, Y.D. Use of Spirulina Biomass Produced from Treatment of Aquaculture Wastewater as Agricultural Fertilizers. Algal Res. 2016, 15, 59-64. [CrossRef]

161. Rayirath, P.; Benkel, B.; Mark Hodges, D.; Allan-Wojtas, P.; MacKinnon, S.; Critchley, A.T.; Prithiviraj, B. Lipophilic Components of the Brown Seaweed, Ascophyllum nodosum, Enhance Freezing Tolerance in Arabidopsis Thaliana. Planta 2009, $230,135-147$. [CrossRef]

162. Shukla, P.S.; Prithiviraj, B. Ascophyllum nodosum Biostimulant Improves the Growth of Zea Mays Grown Under Phosphorus Impoverished Conditions. Front. Plant Sci. 2021, 11, 601843. [CrossRef]

163. Mancuso, S.; Briand, X.; Mugnai, S.; Azzarello, E. Marine Bioactive Substances (IPA Extract) Improve Foliar Ion Uptake and Water Stress Tolerance in Potted "Vitis vinifera" Plants. Adv. Hortic. Sci. 2006, 20, 1000-1006. [CrossRef]

164. Li, Y.; Xu, S.-S.; Gao, J.; Pan, S.; Wang, G.-X. Chlorella Induces Stomatal Closure via NADPH Oxidase-Dependent ROS Production and Its Effects on Instantaneous Water Use Efficiency in Vicia faba. PLoS ONE 2014, 9, e93290. [CrossRef]

165. Rodríguez, A.; Stella, A.; Storni, M.; Zulpa, G.; Zaccaro, M. Effects of Cyanobacterial Extracellular Products and Gibberellic Acid on Salinity Tolerance in Oryza sativa L. Saline Syst. 2006, 2, 7. [CrossRef] [PubMed]

166. El Arroussi, H.; Benhima, R.; Elbaouchi, A.; Sijilmassi, B.; EL Mernissi, N.; Aafsar, A.; Meftah-Kadmiri, I.; Bendaou, N.; Smouni, A. Dunaliella salina Exopolysaccharides: A Promising Biostimulant for Salt Stress Tolerance in Tomato (Solanum lycopersicum). J. Appl. Phycol. 2018, 30, 2929-2941. [CrossRef]

167. Abd El-Baky, H.H.; El-Baz, F.K.; El Baroty, G.S. Enhancing Antioxidant Availability in Wheat Grains from Plants Grown under Seawater Stress in Response to Microalgae Extract Treatments. J. Sci. Food Agric. 2010, 90, 299-303. [CrossRef]

168. Christaki, E.; Bonos, E.; Giannenas, I.; Florou-Paneri, P. Functional Properties of Carotenoids Originating from Algae. J. Sci. Food Agric. 2013, 93, 5-11. [CrossRef]

169. Nowruzi, B.; Porzani, S.J. Toxic Compounds Produced by Cyanobacteria Belonging to Several Species of the Order Nostocales: A Review. J. Appl. Toxicol. 2021, 41, 510-548. [CrossRef]

170. Chaïb, S.; Pistevos, J.C.A.; Bertrand, C.; Bonnard, I. Allelopathy and Allelochemicals from Microalgae: An Innovative Source for Bio-Herbicidal Compounds and Biocontrol Research. Algal Res. 2021, 54, 102213. [CrossRef]

171. Mason, C.P.; Edwards, K.R.; Carlson, R.E.; Pignatello, J.; Gleason, F.K.; Wood, J.M. Isolation of Chlorine-Containing Antibiotic from the Freshwater Cyanobacterium Scytonema hofmanni. Science 1982, 215, 400-402. [CrossRef]

172. Gleason, F.K.; Paulson, J.L. Site of Action of the Natural Algicide, Cyanobacterin, in the Blue-Green Alga, Synechococcus sp. Arch. Microbiol. 1984, 138, 273-277. [CrossRef]

173. Gleason, F.K.; Case, D.E.; Sipprell, K.D.; Magnuson, T.S. Effect of the Natural Algicide, Cyanobacterin, on a Herbicide-Resistant Mutant of Anacystis Nidulans R2. Plant Sci. 1986, 46, 5-10. [CrossRef]

174. Mallipudi, L.R.; Gleason, F.K. Characterization of a Mutant of Anacystis Nidulans R2 Resistant to the Natural Herbicide, Cyanobacterin. Plant Sci. 1989, 60, 149-154. [CrossRef]

175. Arlene Klapes, N. Acute Toxicity of the Natural Algicide, Cyanobacterin, to Daphnia Magna. Ecotoxicol. Environ. Saf. 1990, 20, 167-174. [CrossRef]

176. Bagchi, S.N.; Palod, A.; Chauhan, V.S. Algicidal Properties of a Bloom-Forming Blue-Green Alga, Oscillatoria sp. J. Basic Microbiol. 1990, 30, 21-29. [CrossRef]

177. Chauhan, V.S.; Marwah, J.B.; Bagchi, S.N. Effect of an Antibiotic from Oscillatoria sp. on Phytoplankters, Higher Plants and Mice. New Phytol. 1992, 120, 251-257. [CrossRef]

178. Becher, P.G.; Beuchat, J.; Gademann, K.; Jüttner, F. Nostocarboline: Isolation and Synthesis of a New Cholinesterase Inhibitor from Nostoc 78-12A. J. Nat. Prod. 2005, 68, 1793-1795. [CrossRef] [PubMed]

179. Becher, P.G.; Baumann, H.I.; Gademann, K.; Jüttner, F. The Cyanobacterial Alkaloid Nostocarboline: An Inhibitor of Acetylcholinesterase and Trypsin. J. Appl. Phycol. 2009, 21, 103-110. [CrossRef]

180. Gross, E.M.; Wolk, C.P.; Jüttner, F. Fischerellin, a New Allelochemical from the Freshwater Cyanobacterium Fischerella muscicola. J. Phycol. 1991, 27, 686-692. [CrossRef]

181. Hagmann, L.; Jüttner, F. Fischerellin A, a Novel Photosystem-II-Inhibiting Allelochemical of the Cyanobacterium Fischerella muscicola with Antifungal and Herbicidal Activity. Tetrahedron Lett. 1996, 37, 6539-6542. [CrossRef]

182. Srivastava, A.; Jüttner, F.; Strasser, R.J. Action of the Allelochemical, Fischerellin A, on Photosystem II. Biochim. Biophys. Acta-Bioenerg. 1998, 1364, 326-336. [CrossRef]

183. Jamiołkowska, A. Natural Compounds as Elicitors of Plant Resistance Against Diseases and New Biocontrol Strategies. Agronomy 2020, 10, 173. [CrossRef]

184. Shukla, P.S.; Borza, T.; Critchley, A.T.; Prithiviraj, B. Carrageenans from Red Seaweeds as Promoters of Growth and Elicitors of Defense Response in Plants. Front. Mar. Sci. 2016, 3, 81. [CrossRef]

185. Mercier, L.; Lafitte, C.; Borderies, G.; Briand, X.; Esquerré-Tugayé, M.-T.; Fournier, J. The Algal Polysaccharide Carrageenans Can Act as an Elicitor of Plant Defence. New Phytol. 2001, 149, 43-51. [CrossRef] [PubMed] 
186. Sangha, J.S.; Ravichandran, S.; Prithiviraj, K.; Critchley, A.T.; Prithiviraj, B. Sulfated Macroalgal Polysaccharides $\lambda$-Carrageenan and ı-Carrageenan Differentially Alter Arabidopsis Thaliana Resistance to Sclerotinia sclerotiorum. Physiol. Mol. Plant Pathol. 2010, 75, 38-45. [CrossRef]

187. Graiff, A.; Ruth, W.; Kragl, U.; Karsten, U. Chemical Characterization and Quantification of the Brown Algal Storage Compound Laminarin-A New Methodological Approach. J. Appl. Phycol. 2016, 28, 533-543. [CrossRef]

188. Klarzynski, O.; Plesse, B.; Joubert, J.-M.; Yvin, J.-C.; Kopp, M.; Kloareg, B.; Fritig, B. Linear $\beta-1,3$ Glucans Are Elicitors of Defense Responses in Tobacco. Plant Physiol. 2000, 124, 1027-1038. [CrossRef] [PubMed]

189. Becker, S.; Tebben, J.; Coffinet, S.; Wiltshire, K.; Iversen, M.H.; Harder, T.; Hinrichs, K.-U.; Hehemann, J.-H. Laminarin Is a Major Molecule in the Marine Carbon Cycle. Proc. Natl. Acad. Sci. USA 2020, 117, 6599-6607. [CrossRef]

190. Chen, J.; Yang, J.; Du, H.; Aslam, M.; Wang, W.; Chen, W.; Li, T.; Liu, Z.; Liu, X. Laminarin, a Major Polysaccharide in Stramenopiles. Mar. Drugs 2021, 19, 576. [CrossRef]

191. Klarzynski, O.; Descamps, V.; Plesse, B.; Yvin, J.-C.; Kloareg, B.; Fritig, B. Sulfated Fucan Oligosaccharides Elicit Defense Responses in Tobacco and Local and Systemic Resistance Against Tobacco Mosaic Virus. Mol. Plant-Microbe Interact. 2003, 16, 115-122. [CrossRef]

192. Pearce, R.B.; Ride, J.P. Chitin and Related Compounds as Elicitors of the Lignification Response in Wounded Wheat Leaves. Physiol. Plant Pathol. 1982, 20, 119-123. [CrossRef]

193. Roby, D.; Gadelle, A.; Toppan, A. Chitin Oligosaccharides as Elicitors of Chitinase Activity in Melon Plants. Biochem. Biophys. Res. Commun. 1987, 143, 885-892. [CrossRef]

194. Kaku, H.; Nishizawa, Y.; Ishii-Minami, N.; Akimoto-Tomiyama, C.; Dohmae, N.; Takio, K.; Minami, E.; Shibuya, N. Plant Cells Recognize Chitin Fragments for Defense Signaling through a Plasma Membrane Receptor. Proc. Natl. Acad. Sci. USA 2006, 103, 11086-11091. [CrossRef]

195. Shimizu, T.; Nakano, T.; Takamizawa, D.; Desaki, Y.; Ishii-Minami, N.; Nishizawa, Y.; Minami, E.; Okada, K.; Yamane, H.; Kaku, H.; et al. Two LysM Receptor Molecules, CEBiP and OsCERK1, Cooperatively Regulate Chitin Elicitor Signaling in Rice: LysM Receptors for Rice Chitin Signaling. Plant J. 2010, 64, 204-214. [CrossRef] [PubMed]

196. Elieh-Ali-Komi, D.; Hamblin, M.R. Chitin and Chitosan: Production and Application of Versatile Biomedical Nanomaterials. Int. J. Adv. Res. 2016, 4, 411-427.

197. Bastiaens, L.; Soetemans, L.; D'Hondt, E.; Elst, K. Sources of Chitin and Chitosan and Their Isolation. In Chitin and Chitosan; Broek, L.A.M., Boeriu, C.G., Eds.; Wiley: Hoboken, NJ, USA, 2019; pp. 1-34. ISBN 978-1-119-45043-6.

198. Chiriboga, O.G.; LeDuff, P.; Rorrer, G.L. Extracellular Chitin Nanofibers from Marine Diatoms. In Encyclopedia of Marine Biotechnology; Kim, S., Ed.; Wiley: Hoboken, NJ, USA, 2020; pp. 1083-1092. ISBN 978-1-119-14377-2.

199. Ozkan, A.; Rorrer, G.L. Effects of CO2 Delivery on Fatty Acid and Chitin Nanofiber Production during Photobioreactor Cultivation of the Marine Diatom Cyclotella sp. Algal Res. 2017, 26, 422-430. [CrossRef]

200. Korunic, Z. ReviewDiatomaceous Earths, a Group of Natural Insecticides. J. Stored Prod. Res. 1998, 34, 87-97. [CrossRef]

201. Ruan, J.; Zhou, Y.; Zhou, M.; Yan, J.; Khurshid, M.; Weng, W.; Cheng, J.; Zhang, K. Jasmonic Acid Signaling Pathway in Plants. Int. J. Mol. Sci. 2019, 20, 2479. [CrossRef]

202. Seyfferth, C.; Tsuda, K. Salicylic Acid Signal Transduction: The Initiation of Biosynthesis, Perception and Transcriptional Reprogramming. Front. Plant Sci. 2014, 5, 697. [CrossRef]

203. Li, N.; Han, X.; Feng, D.; Yuan, D.; Huang, L.-J. Signaling Crosstalk between Salicylic Acid and Ethylene/Jasmonate in Plant Defense: Do We Understand What They Are Whispering? Int. J. Mol. Sci. 2019, 20, 671. [CrossRef]

204. De Nys, R.; Steinberg, P.D.; Willemsen, P.; Dworjanyn, S.A.; Gabelish, C.L.; King, R.J. Broad Spectrum Effects of Secondary Metabolites from the Red Alga Delisea pulchra in Antifouling Assays. Biofouling 1995, 8, 259-271. [CrossRef]

205. Kjelleberg, S.; Steinberg, P.; Givskov, M.; Gram, L.; Manefield, M.; de Nys, R. Do Marine Natural Products Interfere with Prokaryotic AHL Regulatory Systems? Aquat. Microb. Ecol. 1997, 13, 85-93. [CrossRef]

206. Bhowmick, S.; Mazumdar, A.; Moulick, A.; Adam, V. Algal Metabolites: An Inevitable Substitute for Antibiotics. Biotechnol. Adv. 2020, 43, 107571. [CrossRef]

207. Manefield, M.; Welch, M.; Givskov, M.; Salmond, G.P.C.; Kjelleberg, S. Halogenated Furanones from the Red Alga, Delisea pulchra, Inhibit Carbapenem Antibiotic Synthesis and Exoenzyme Virulence Factor Production in the Phytopathogen Erwinia carotovora. FEMS Microbiol. Lett. 2001, 205, 131-138. [CrossRef] [PubMed]

208. Hentzer, M.; Riedel, K.; Rasmussen, T.B.; Heydorn, A.; Andersen, J.B.; Parsek, M.R.; Rice, S.A.; Eberl, L.; Molin, S.; Høiby, N.; et al. Inhibition of Quorum Sensing in Pseudomonas Aeruginosa Biofilm Bacteria by a Halogenated Furanone Compound. Microbiology 2002, 148, 87-102. [CrossRef] [PubMed]

209. Manefield, M.; de Nys, R.; Naresh, K.; Roger, R.; Givskov, M.; Peter, S.; Kjelleberg, S. Evidence That Halogenated Furanones from Delisea pulchra Inhibit Acylated Homoserine Lactone (AHL)-Mediated Gene Expression by Displacing the AHL Signal from Its Receptor Protein. Microbiology 1999, 145, 283-291. [CrossRef] [PubMed]

210. Manefield, M.; Rasmussen, T.B.; Henzter, M.; Andersen, J.B.; Steinberg, P.; Kjelleberg, S.; Givskov, M. Halogenated Furanones Inhibit Quorum Sensing through Accelerated LuxR Turnover. Microbiology 2002, 148, 1119-1127. [CrossRef]

211. Teplitski, M.; Chen, H.; Rajamani, S.; Gao, M.; Merighi, M.; Sayre, R.T.; Robinson, J.B.; Rolfe, B.G.; Bauer, W.D. Chlamydomonas reinhardtii Secretes Compounds That Mimic Bacterial Signals and Interfere with Quorum Sensing Regulation in Bacteria. Plant Physiol. 2004, 134, 137-146. [CrossRef] 
212. Natrah, F.M.I.; Kenmegne, M.M.; Wiyoto, W.; Sorgeloos, P.; Bossier, P.; Defoirdt, T. Effects of Micro-Algae Commonly Used in Aquaculture on Acyl-Homoserine Lactone Quorum Sensing. Aquaculture 2011, 317, 53-57. [CrossRef]

213. Kwan, J.C.; Meickle, T.; Ladwa, D.; Teplitski, M.; Paul, V.; Luesch, H. Lyngbyoic Acid, a “Tagged” Fatty Acid from a Marine Cyanobacterium, Disrupts Quorum Sensing in Pseudomonas Aeruginosa. Mol. BioSyst. 2011, 7, 1205. [CrossRef]

214. Kwan, J.C.; Teplitski, M.; Gunasekera, S.P.; Paul, V.J.; Luesch, H. Isolation and Biological Evaluation of 8-Epi-Malyngamide C from the Floridian Marine Cyanobacterium Lyngbya majuscula. J. Nat. Prod. 2010, 73, 463-466. [CrossRef]

215. Watanabe, K.; Umeda, K.; Kurita, Y.; Takayama, C.; Miyakado, M. Two Insecticidal Monoterpenes, Telfairine and Aplysiaterpenoid A, from the Red Alga Plocamium telfairiae: Structure Elucidation, Biological Activity, and Molecular Topographical Consideration by a Semiempirical Molecular Orbital Study. Pestic. Biochem. Physiol. 1990, 37, 275-286. [CrossRef]

216. Zemolin, A.P.P.; Cruz, L.C.; Paula, M.T.; Pereira, B.K.; Albuquerque, M.P.; Victoria, F.C.; Pereira, A.B.; Posser, T.; Franco, J.L. Toxicity Induced by Prasiola crispa to Fruit Fly Drosophila melanogaster and Cockroach Nauphoeta cinerea: Evidence for Bioinsecticide Action. J. Toxicol. Environ. Health Part A 2014, 77, 115-124. [CrossRef]

217. Holken Lorensi, G.; Soares Oliveira, R.; Leal, A.P.; Zanatta, A.P.; Moreira de Almeida, C.G.; Barreto, Y.C.; Eduarda Rosa, M.; de Brum Vieira, P.; Brito Ramos, C.J.; de Carvalho Victoria, F.; et al. Entomotoxic Activity of Prasiola crispa (Antarctic Algae) in Nauphoeta cinerea Cockroaches: Identification of Main Steroidal Compounds. Mar. Drugs 2019, 17, 573. [CrossRef]

218. Rapp, J.; Wagner, B.; Brilisauer, K.; Forchhammer, K. In Vivo Inhibition of the 3-Dehydroquinate Synthase by 7-Deoxysedoheptulose Depends on Promiscuous Uptake by Sugar Transporters in Cyanobacteria. Front. Microbiol. 2021, 12, 692986. [CrossRef]

219. Herrmann, K.M.; Weaver, L.M. The Shikimate Pathway. Annu. Rev. Plant Physiol. Plant Mol. Biol. 1999, 50, 473-503. [CrossRef]

220. Fenoradosoa, T.A.; Ali, G.; Delattre, C.; Laroche, C.; Petit, E.; Wadouachi, A.; Michaud, P. Extraction and Characterization of an Alginate from the Brown Seaweed Sargassum turbinarioides Grunow. J. Appl. Phycol. 2010, 22, 131-137. [CrossRef]

221. Guiry, M.D. How Many Species of Algae Are There? J. Phycol. 2012, 48, 1057-1063. [CrossRef] 